
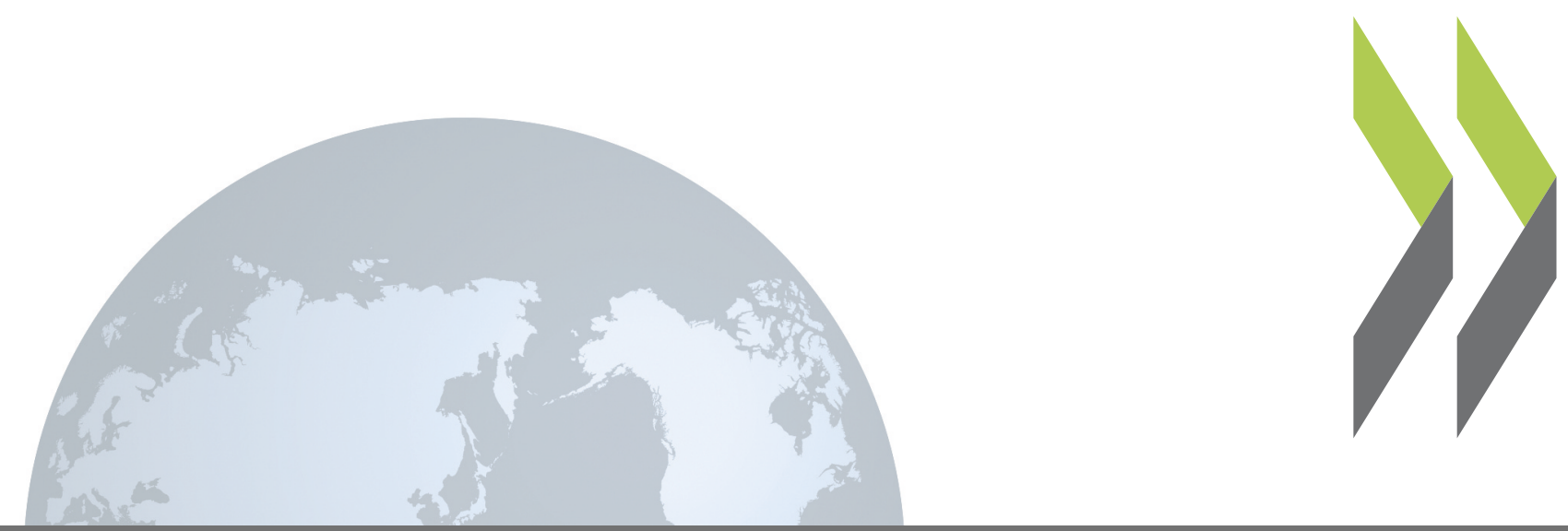

SIGMA Papers No. 34

\title{
Achieving High Quality in the Work of Supreme Audit Institutions
}

OECD 
Organisation de Coopération et de Développement Economiques

Organisation for Economic Co-operation and Development

14-Jun-2005

PUBLIC GOVERNANCE AND TERRITORIAL DEVELOPMENT DIRECTORATE

English - Or. English

SIGMA - A JOINT INITIATIVE OF THE OECD AND THE EUROPEAN UNION, PRINCIPALLY FINANCED BY THE EU

ACHIEVING HIGH QUALITY IN THE WORK OF SUPREME AUDIT INSTITUTIONS

SIGMA PAPER No. 34, 2004

For further information, please contact Nicolas John Treen, Senior Adviser of the Financial Control Management Programme in SIGMA. Tel: +33 (0)1 45248356 - Fax: +33 (0)1 45241300.

Email: nicolasjohn.treen@oecd.org 
GOV/SIGMA(2004)1 


\section{FOREWORD}

This paper, focusing on the issue of how to achieve high quality in the audit process, is an outgrowth of a report on audit quality control and a subsequent set of guidelines for audit quality, both of which were prepared at the direction of the Presidents of the Supreme Audit Institutions (SAIs) of the Central and Eastern European Countries, Cyprus, Malta and Turkey and of the European Court of Auditors. In view of the importance of the subject, SIGMA has prepared this paper for distribution to a wider audience.

SIGMA is publishing this paper in the belief that the information it contains should be of broad interest, both to those involved in government auditing and to those who use the audit reports and other products developed by SAIs. Ensuring the high quality of those reports is a vital factor in the chain of accountability and the effectiveness of public sector governance.

SIGMA appreciates the efforts of all those who developed the information on which this paper is based. This includes representatives of the SAIs of Albania, Bulgaria, Croatia, Cyprus, the Czech Republic, Estonia, Hungary, Latvia, Lithuania, Malta, Poland, Romania, Slovakia, Slovenia and Turkey and of the ECA - the "participant SAIs" - who contributed to the underlying study and guidelines. We especially appreciate the work of the Expert Group on Audit Quality in preparing the guidelines referred to above. The Expert Group comprised the Supreme Chamber of Control of Poland (Najwy sza Izba Kontroli), the National Audit Office of Malta (Ufficcju Nazzjonali tal-Verifika), the State Audit Office of Hungary (Allami Szamvevoszek), and the Court of Accounts of France (Cour des Comptes).

Important contributions were also made by representatives of other EU SAIs, who provided information about quality practices in their organisations. Special thanks must be given to Harry Havens (formerly of the US Government Accountability Office), and Annes McGoogan, Pamela Barnes Edwards and Patricia Prinsen Geerligs from SIGMA, for their excellent work on the paper.

For further information, please contact Nick Treen, SIGMA Principal Administrator, External Audit and Financial Control, at the address shown below.

This document and other SIGMA papers are available on the SIGMA web site: www.SIGMAweb.orghttp:///

OECD, 2 rue Andre Pascal, 75775 Paris Cedex 16

email: nicolasjohn.treen@oecd.org or SIGMA.contact@oecd.org

This document has been produced with the financial assistance of the European Union. The views expressed herein can in no way be taken to reflect the official opinion of the European Union and do not necessarily reflect the views of the OECD and its Member countries or of the beneficiary countries participating in the SIGMA Programme. 


\section{TABLE OF CONTENTS}

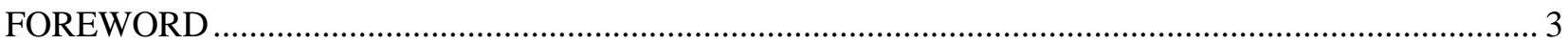

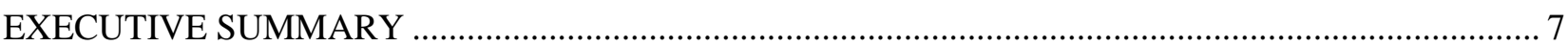

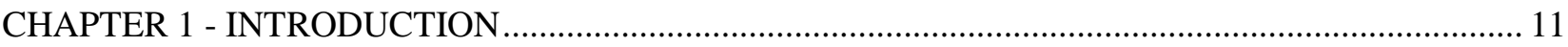

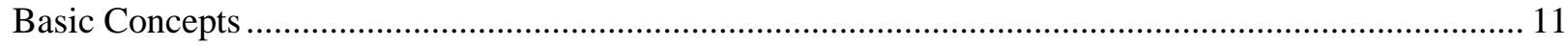

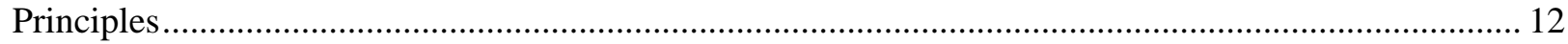

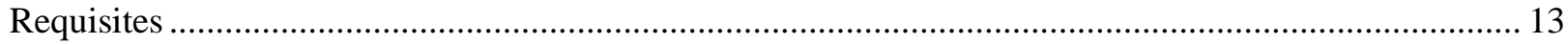

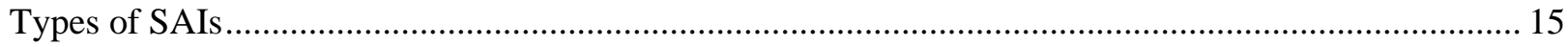

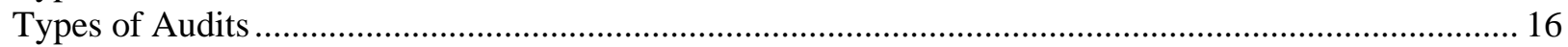

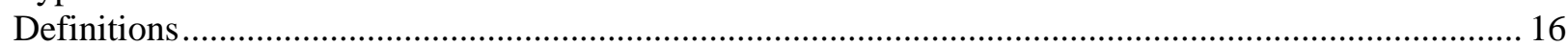

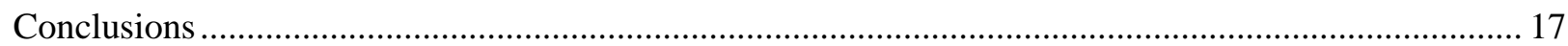

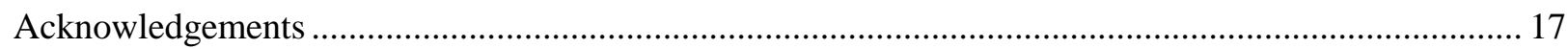

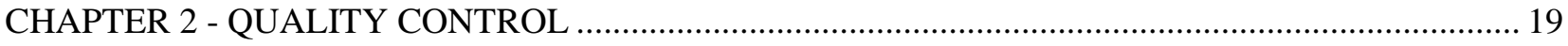

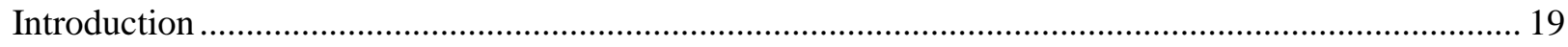

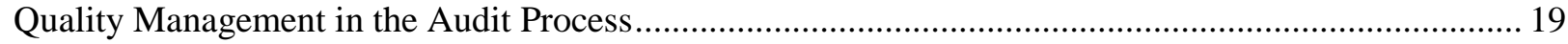

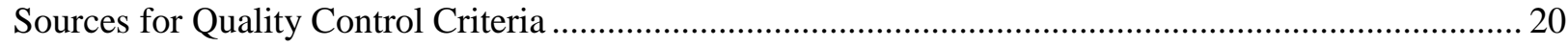

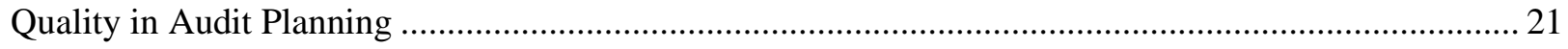

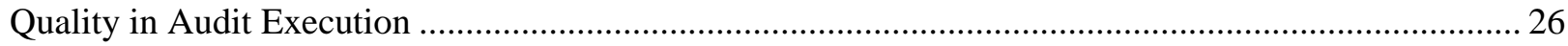

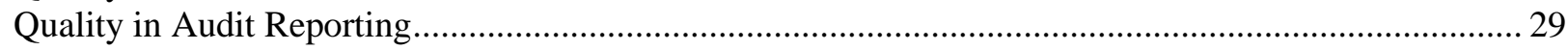

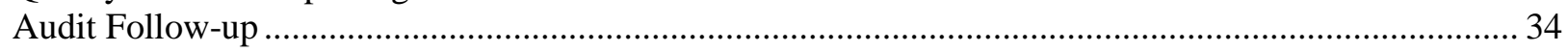

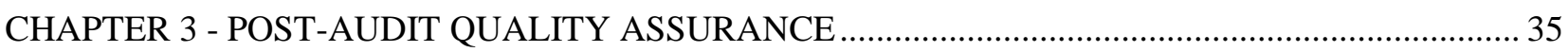

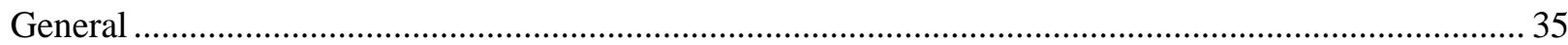

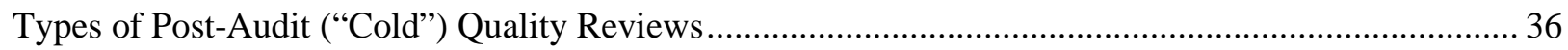

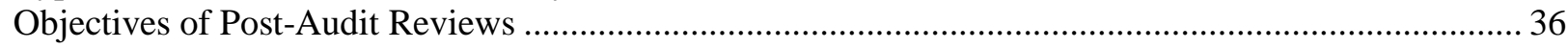

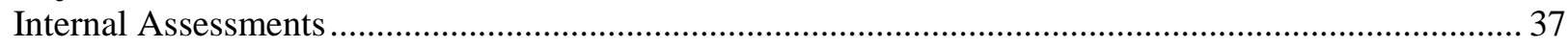

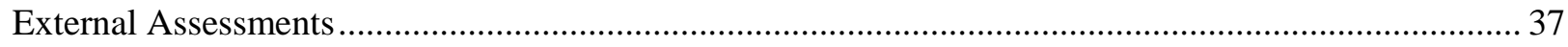

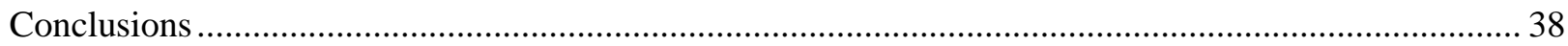

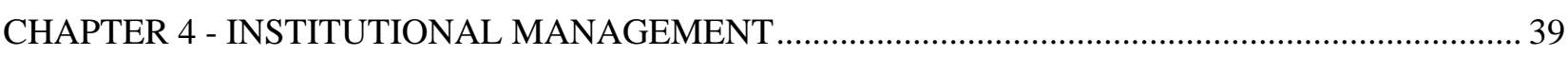

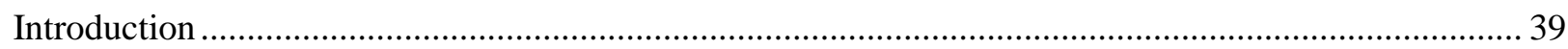

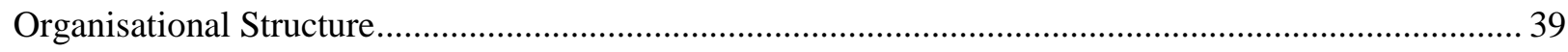

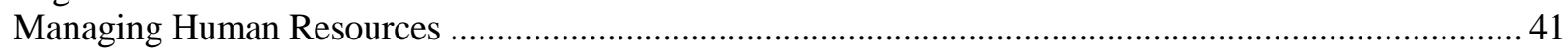

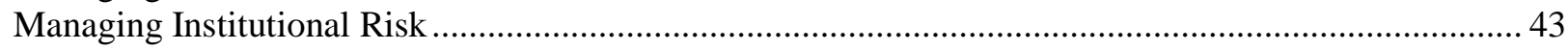

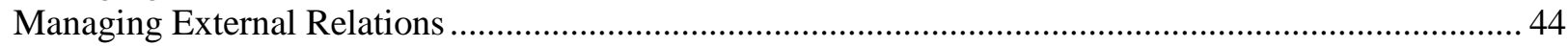

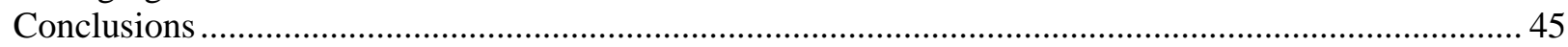

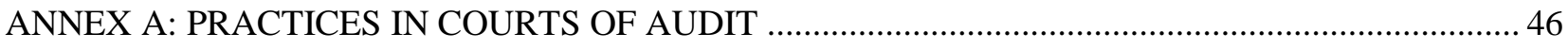

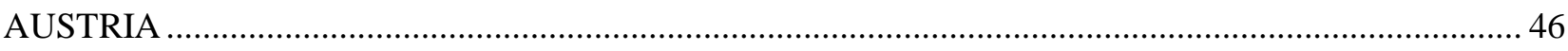

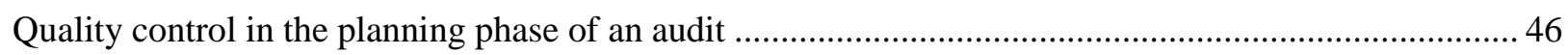

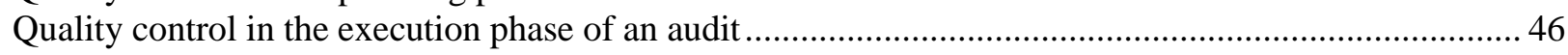

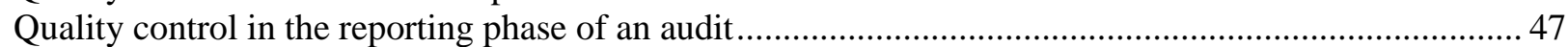


Practical problems in operating Quality Control procedures and lessons learned .................................. 48

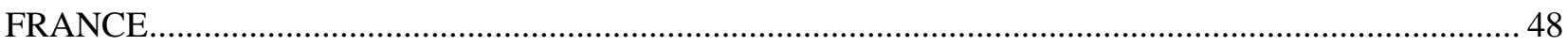

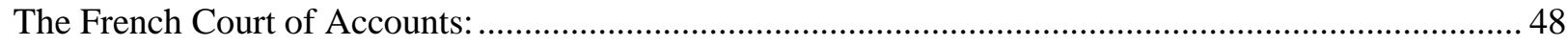

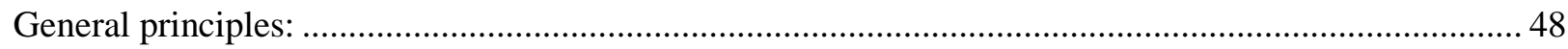

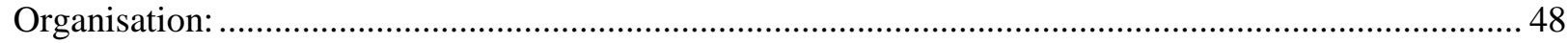

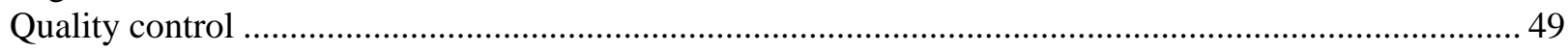

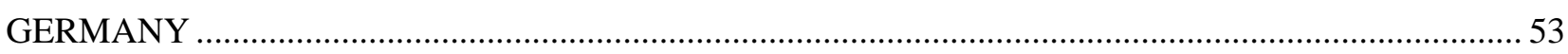

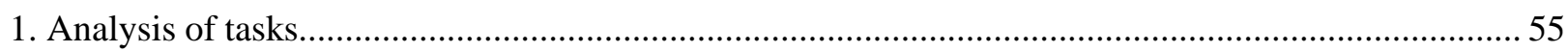

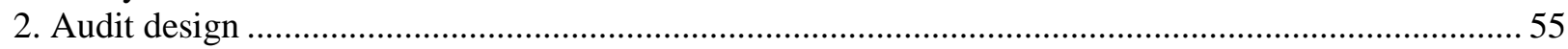

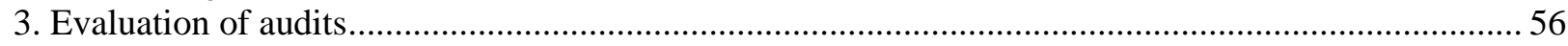

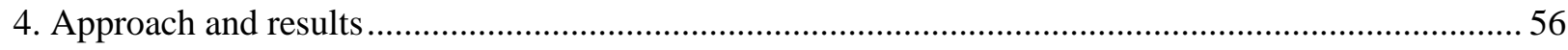

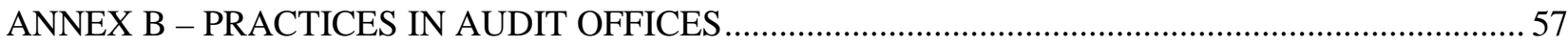

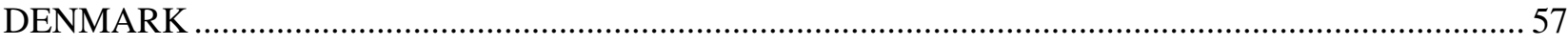

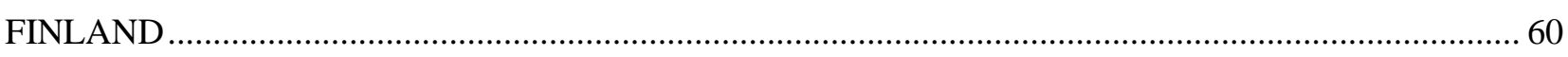

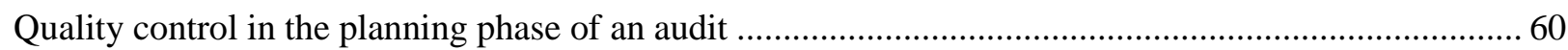

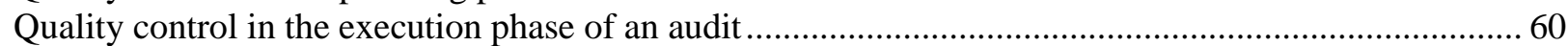

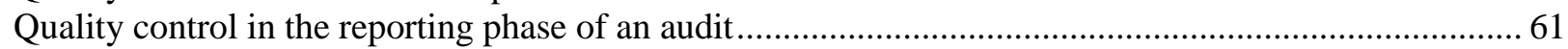

Practical problems in operating the Quality Control procedures and lessons learned ............................ 61

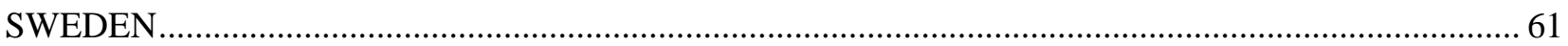

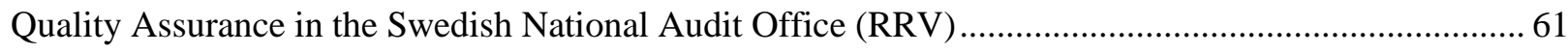

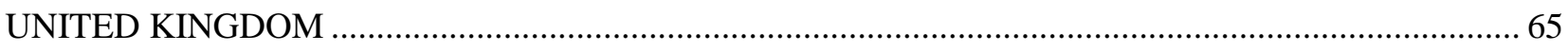

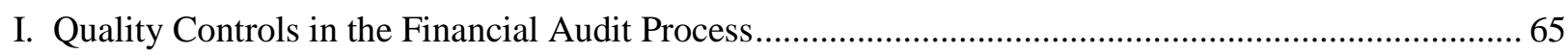

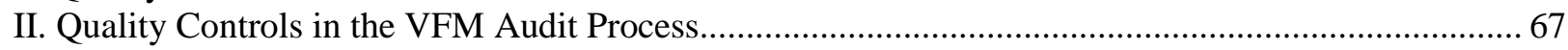

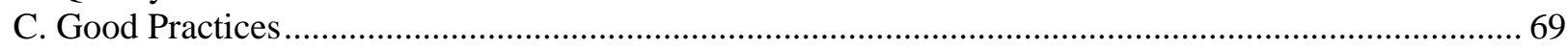

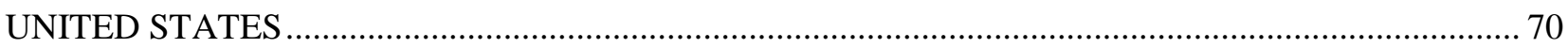

Quality Assurance in the United States General Accounting Office (GAO) .......................................... 70

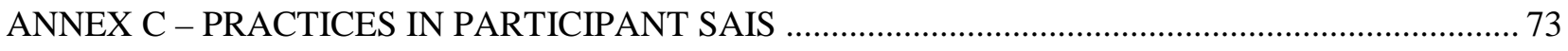

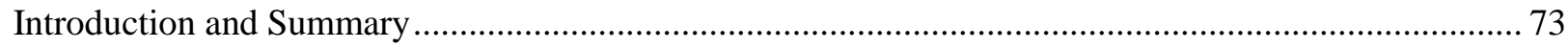

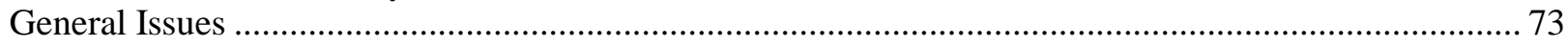

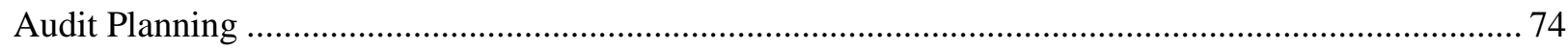

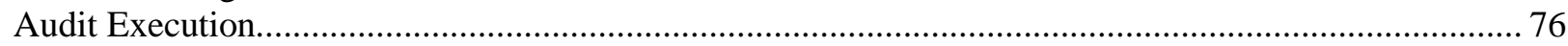

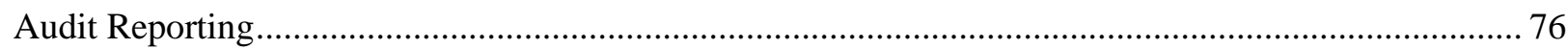

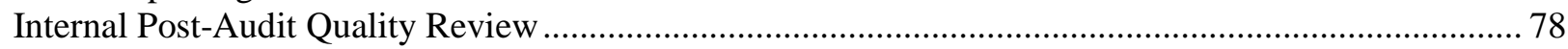

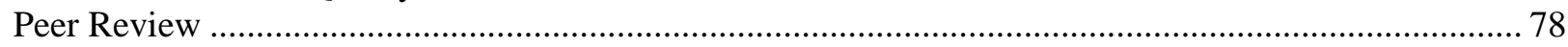

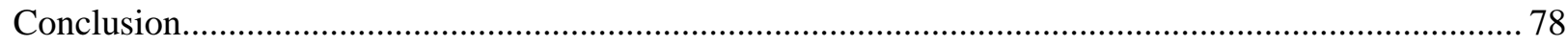

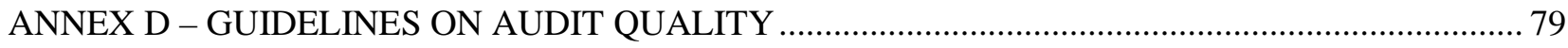

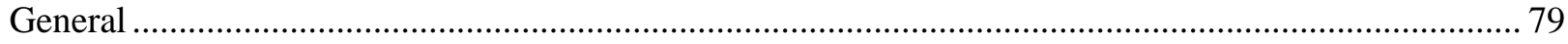

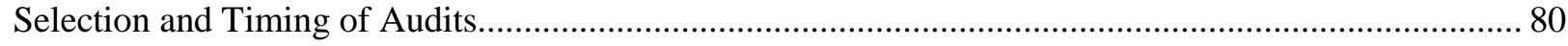

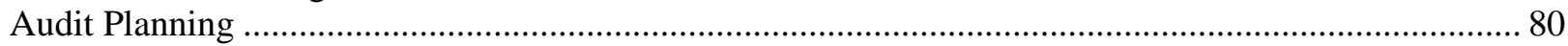

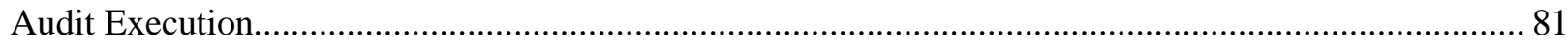

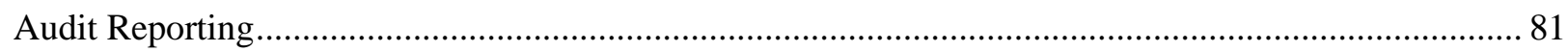

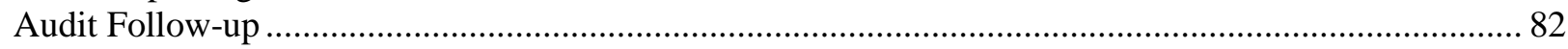

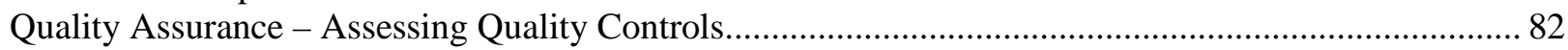




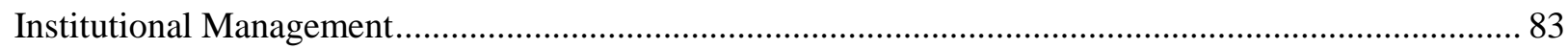

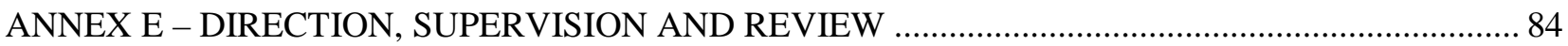

Direction, Supervision and Review in Decentralised Courts of Audit................................................... 84

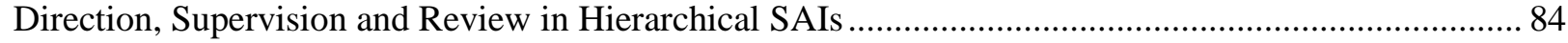

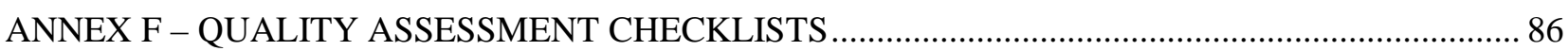

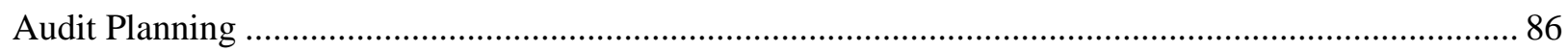

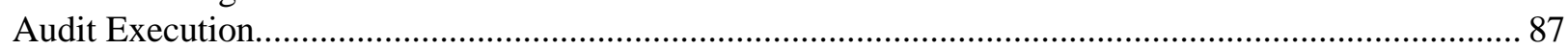

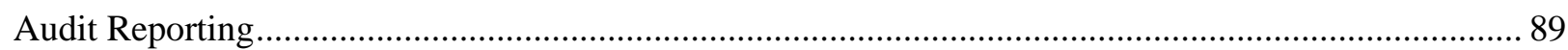

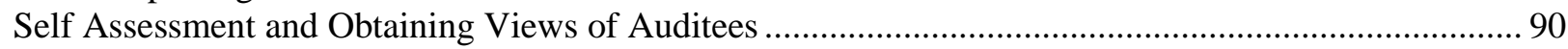

ANNEX G - ISSUES INVOLVED IN POST-AUDIT REVIEWS _........................................................ 92

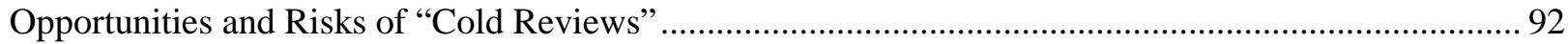

What Post-Audit Reviewers may examine in Regularity Audits ........................................................... 92

What Post-Audit Reviewers may examine in Performance Audits....................................................... 93

Required Elements for Post-Audit Reviewers...................................................................................... 93 


\section{EXECUTIVE SUMMARY}

This paper focuses primarily on the issue of how to achieve high quality in the audit process. In addition to describing the types of procedures needed to achieve quality, however, it discusses basic principles and those matters of institutional management that create an environment that encourages high quality in an SAI's work.

Audit quality is obtained by a process of identifying and administering the activities needed to achieve the quality objectives of an SAI. All types of SAIs need to understand the benefits that can be realised once audit quality is made a top priority. Improving audit quality requires a systematic SAI-wide approach. Piecemeal efforts by individuals and individual audit teams are not enough and will not work. There are no quick fixes to be obtained where audit quality is concerned. SAIs need to proceed methodically in an organised way to fix each quality issue and problem in turn. As new problems will always emerge, this should be a continuous process for the SAI. It is also evident that most audit quality-related problems are mainly the result of poor management of the audit process or of the SAI itself.

Ensuring high levels of quality in an audit organisation involves a succession of detailed steps that must be taken over a period of time. In fact, it is a never-ending process of continual improvement. The first requirement is to define the standards of quality and then to put quality control procedures in place that will ensure that these standards are met. These procedures need not - and should not - suppress the initiative and good judgement of the auditor in adapting to particular circumstances. However, if the auditor judges that it is necessary to depart from the usual audit techniques, it is incumbent upon the auditor to demonstrate the necessity of doing so, and to show that the approach he or she has chosen is capable of satisfying the audit objectives.

The next stage in the evolution of an SAI's quality management involves the assurance that quality control procedures are working effectively together with the identification of ways of improving the effectiveness and/or efficiency of these procedures. The best technique for accomplishing this is the use of various types of post-audit quality reviews and the use of peer review concepts for institutional issues.

Achieving true excellence requires going even further. It requires building an institutional culture in which high quality is a fundamental value that is reflected in the leadership management competencies of the SAI and in its relations with other institutions.

Chapter 1 sets out the basic concepts, principles and requisites that must underlie an effective approach to ensuring the high quality of an SAI's audit work and reports. This includes such matters as:

- a Code of Professional Ethics

- adoption and adherence to International Auditing Standards

- appropriate resources and organisational structure

- manuals and guidance

- capable staff 


\section{GOV/SIGMA(2004)1}

- quality management policies and guidance

- continuous learning and improvement

Chapter 2 draws on international experience to set out a number of "good practices" involved in the audit process. To build high quality into the audit process, an SAI should:

- ensure effective direction, supervision and review during all phases of the audit process;

- $\quad$ specify clearly the roles and responsibilities of each of the participants in each phase;

- identify and document the quality control criteria applicable to each phase and the sources from which those criteria were drawn; and

- clearly establish the quality control procedures to be followed during each phase and document both the implementation of those procedures and the results.

Chapter 3 discusses ways of ensuring that the quality control processes that an SAI has put in place are operating effectively. Experience has demonstrated that the most effective means of accomplishing this is the post-audit quality review.

The purpose of such reviews is not to criticise the particular audit being examined, but rather to ascertain whether or not the quality control procedures established by an SAI are consistently and properly used and are effective, and to identify ways in which the controls can be improved.

One form of such a review is carried out internally, by experienced auditors within the SAI who are independent of the audit under review. These reviews should be performed on a selected sample of audits annually.

The second form is an external review, performed by experts (peers) from relevant professional organisations or from SAIs in other countries. External reviews should be performed at intervals of several years.

Chapter 4 describes ways in which the overall management of an SAI can contribute to the quality and effectiveness of its work. Quality control and quality assurance systems and procedures are essential for ensuring that an SAI's audit reports and other products meet a minimum standard of quality. In fact, however, an SAI should seek to go beyond such minimums. This requires that the management of the SAI be skilled, not only in the techniques of auditing, but also in the techniques of management. These are skills that some managers acquire through experience, but they also can be - and often are - learned and enhanced through effective training. They range from the ability to lead and inspire the professional and support staff on a day-to-day basis to the more wide-ranging skills of budgeting and strategic planning. The most successful SAIs invest considerable time and resources in ensuring that managers at all levels of the organisation continuously enhance these skills.

To pursue the goal of highest quality, an SAI should:

- develop a management structure that ensures effective, efficient use of SAI resources;

- manage its human resources effectively, to maximise the productivity of the staff, including the following elements: 
seek excellence in the recruitment process, while also recruiting to meet the anticipated future needs of the SAI;

develop and deliver effective training of four types:

introductory training, to help new personnel adapt to the organisation;

technical training, to increase the skills of staff members;

$\square$ managerial training, to prepare staff members for greater responsibilities; and

$\square$ continuing education, to ensure that staff maintain and enhance their professional skills and knowledge.

encourage staff development through:

$\square$ formal performance appraisal systems to identify strengths and weaknesses;

$\square$ individual development plans to build on strengths and overcome weaknesses; and

$\square$ minimum professional development standards as a prerequisite for promotion.

recognise the need for specialised skills in performing certain audits and arrange for the availability of needed specialists, either within the SAI or from external sources.

- $\quad$ assess the risks that the SAI faces in its audit work and manage those risks effectively, such as by assigning more experienced auditors to audits involving higher than usual risks and by intensifying supervision and review of those audits;

- manage effectively the external relations that are vital to the overall effectiveness of the SAI in improving accountability, economy, efficiency and effectiveness in government entities. Of special importance, in addition to working with parliament, the subject of a prior SIGMA paper ${ }^{1}$, are:

ministry of finance

$>$ line ministries and state agencies

$>$ the media

$>$ private sector auditors and relevant professional organisations

the academic community

Annex A describes quality assurance practices in selected audit courts.

Annex B provides comparable descriptions for selected audit offices.

${ }^{1}$ Relations between Supreme Audit Institutions and Parliamentary Committees, SIGMA Paper No. 33, CCNM/GOV/SIGMA(2002)1, 9 December 2002. Available on the SIGMA web site: www.SIGMAweb.org. 
Annex C summarises the practices in the participant SAIs.

Annex D sets out the guidelines as approved by the SAI presidents, with minor modifications to reflect subsequent discussions.

Annex $\mathbf{E}$ discusses the functions of direction, supervision and review and how these can be performed effectively in various types of SAIs.

Annex F contains several checklists that may be helpful for those reviewing the quality of an SAI's work.

Annex G discusses some of the issues involved in conducting post-audit quality reviews.

While all SAIs do seek conscientiously to ensure high quality in their audit work, considerably more attention still needs to be given to this issue on the part of many SAIs. This paper suggests some good ways of going about that task. 


\section{CHAPTER 1 - INTRODUCTION}

\section{Basic Concepts}

An audit report is the end product of an audit process reviewing an entity, programme or activity. Quality control and quality assurance provide reasonable assurance that the audit has examined significant matters and that the results of the audit, as contained in the audit report, are an accurate reflection, in all material respects, of the true conditions of the matters under consideration.

Achieving and maintaining high quality throughout the audit process is essential if an SAI is to accomplish its central mission of improving accountability and performance in the state sector.

Audit quality is obtained by identifying and administering the activities needed to achieve the quality objectives of an SAI. Improving audit quality requires a systematic SAI-wide approach; piecemeal efforts by individual auditors and audit teams are not enough and will not work. There are no quick fixes to be obtained where audit quality is concerned. SAIs need to proceed methodically in an organised way to fix each quality issue and problem in turn; and as new problems will always emerge, this should be a continuous process.

In discussing the work of an SAI, the term "quality" involves several attributes, including:

- Significance - How important is the matter that was examined in the audit? This, in turn, can be assessed in several dimensions, such as the financial size of the auditee and the effects the auditee has on the public at large or on major national policy issues.

- Reliability - Are the audit findings and conclusions an accurate reflection of actual conditions with respect to the matter being examined? Are all assertions in the audit report or other product fully supported by the data gathered in the audit? Is all material evidence that was gathered in the audit properly reflected in the opinion or findings and conclusions?

- Objectivity - Was the audit carried out in an objective and fair manner, without favour or prejudice? The auditor should base his assessment and opinion purely on facts and sound analysis.

- Scope - Did the audit task plan properly address all elements needed for a successful audit? Did execution of the audit satisfactorily complete all the needed elements of the task plan?

- Timeliness - Were the audit results delivered at an appropriate time? This may involve meeting a legal or statutory deadline, or delivering audit results when they are needed for a policy decision or when they will be most useful in correcting management weaknesses.

- Clarity - Was the audit report clear and concise in presenting the results of the audit? This typically involves being sure that the scope, findings and any recommendations can be readily understood by busy executives and parliamentarians who may not be experts in the matters that are addressed but may need to act in response to the report.

- Efficiency - Were the resources assigned to the audit reasonable in light of the significance and complexity of the audit?

- Effectiveness - Did the findings, conclusions and recommendations get an appropriate response from the auditee, the government and/or parliament? 
GOV/SIGMA(2004)1

\section{Principles}

\section{Prague Recommendation on Quality Management}

Recommendation 7 of the "Recommendations concerning the Functioning of Supreme Audit Institutions in the Context of European Integration" (the "Prague Recommendations") states:

"Supreme Audit Institutions should ensure that their human and financial resources are used in the most efficient way to secure the effective exercise of their mandate. To this end, SAI management will need to develop and institute appropriate policies and measures to help guarantee that the SAI is competently organised to deliver high-quality and effective audit work and reports."

\section{Conforming to International Auditing Standards}

- An SAI should ensure that state audit legislation is in line with the Lima Declaration of Auditing Precepts and INTOSAI Auditing Standards. If inconsistencies exist, parliament should be encouraged to undertake the necessary legislative amendments.

- Professional standards, based on the INTOSAI Auditing Standards, the European Implementing Guidelines for INTOSAI Auditing Standards and IFAC International Standards on Auditing, should be adopted by an SAI and promulgated to its audit staff.

- An SAI should only carry out audits for which it has legal authority.

\section{Code of Professional Ethics}

- An SAI should develop and promulgate a Code of Professional Ethics that is applicable to the institution itself and to all its personnel. This Code would help instil in the organisation a culture of professionalism in audit work that is conducive to quality in the audit product. Matters commonly discussed in an SAI Code of Ethics relate to trust, confidentiality, credibility; integrity; independence, objectivity, impartiality, political neutrality; conflicts of interest; professional secrecy; competence; and professional development (for further guidance, see the INTOSAI Code of Ethics).

- This code could be given further impact by having all SAI employees sign a declaration that would commit them to respect the Code of Ethics of the SAI and adhere to SAI directives. In addition, some SAIs require all staff to undergo periodic training to remind them of the SAI's ethical standards and/or require periodic supervisory review of each employee's investment activity, personal relationships and professional activities to ensure continued compliance with the ethical standards, especially those governing conflicts of interest.

SAIs should also refer to other valuable guidance, including the Code of Ethics and Auditing Standards and the Implementation Guidelines for Performance Auditing of the International Organisation of Supreme Audit Institutions (INTOSAI) and the European Implementing Guidelines for the INTOSAI Auditing Standards issued by the European Court of Auditors (especially current Guideline 51, "Quality Assurance").

SAIs should take note of current IFAC Standards. While these specifically apply to financial statement (attestation) audits, they provide guidance that can be helpful in other audit situations as well. 


\section{Requisites}

The objective of an SAI is not simply to carry out audits in terms of its legislation, but to provide audit work and audit results that are of a consistently high quality. In order to achieve this purpose, an SAI needs to develop, clearly explain to concerned staff, and effectively implement a whole range of structures, processes and procedures which ensure that audit reports and other outputs - of whatever kind - are of good quality, have identified the major risks, are effective, have been efficiently and economically prepared, are supported by well documented facts, are seen to be useful, and have produced useful results through their comments and recommendations.

\section{Quality Management Policies}

Setting up and implementing quality management policies are the responsibility primarily of the top management. They will vary significantly depending on the type and organisation of the SAI and the type of audits that it carries out.

The policies affect (i) the SAI as an organisation; (ii) the staff who work in the SAI, especially those who are directly involved in audits or who provide essential support to audits; and (iii) the audit process itself.

The following policies, if adopted and implemented by an SAI, can help ensure that proper practices and procedures are in place that facilitate audit tasks, minimise the risks that may be encountered in the audit process and ensure that audits are carried out competently and effectively:

\section{Manuals and Guidance}

- Policies and standards should be established that define how tasks should be planned, carried out and reported upon.

- Manuals and other written guidance and instructions concerning the conduct of audits should be developed, promulgated to and followed by all audit staff.

- As manuals and other guidance change, SAI staff should receive effective training to ensure that they understand and can comply with the new requirements.

\section{Capable Staffing}

- Persons with suitable qualifications, skills, competence and aptitude for audit work should be recruited. Professional recruitment procedures ensure that the right staff are engaged by an SAI.

- SAI employees should be trained (both formal and on-the-job training) and have their skills developed to enable them to perform their duties effectively and to develop professionally throughout their careers. They should be able to advance within the audit organisation, in line with standing SAI procedures.

- An SAI should ensure that a sufficient number of people, with the appropriate skills and competence, are assigned to an audit.

- An SAI should identify gaps in skills and competence in order to plan for specific audits, including possible use of external experts. 


\section{Measures and Guidance related to Quality Management Policies}

- Proper delegation, direction, supervision and review of work should be carried out in a manner that provides reasonable assurance that audit planning, execution, reporting and follow-up have been performed competently.

- Proper communication processes should apply throughout the organisation to ensure that audit tasks and other requirements are clearly understood and followed by all concerned. Feedback should always be encouraged at all levels of the organisation.

- An SAI should adopt approved work programmes and plans that clearly set out the audit objectives, auditing methods to be used, responsibilities, budgets, expertise required, timetables and staff allocations.

- Procedures should be applied during the execution of audit tasks to ensure adherence to policies, standards and methodologies. Where applicable, tools, such as software packages, should be provided to assist auditors in following the proper procedures.

- Complete, appropriate, clear and concise documentation, in a standardised format, should be required to support audit evidence.

- Protocols should be established to regulate relations with auditees and other stakeholders.

- Reporting format and procedures should be in accordance with applicable laws and the SAI's own policies.

- Proper security, access and file retention procedures should exist to ensure confidentiality and proper maintenance of such files.

- A suitable workplace should be established where auditors have proper working conditions and an appropriate environment in which to work.

\section{Continuous Learning and Improvement}

- In line with the Lima Declaration on Auditing Precepts, audit methods (in particular for financial audits) should always be adapted to the progress of the sciences and techniques relating to financial management. In a similar way, for performance audits, audit methods should be adapted to developments in data gathering and information analysis techniques.

- Audit staff should be encouraged to further develop their professional qualifications and knowledge. In some countries, private and/or public audit organisations require their employees to annually undergo a certain number of hours of courses, seminars and other forms of relevant education as a prerequisite for continued certification and/or promotion.

- Efficiency and effectiveness of internal standards and procedures should be periodically reviewed to rectify shortcomings and make improvements. Such a continuous improvement process helps ensure that the quality system of the SAI continues to evolve in the right direction.

- An SAI should establish benchmarks and other performance measures to monitor its work over time and to allow comparison with the performance of other similar institutions. 
- Interaction and frequent communication and contacts between an SAI and other local and international professional bodies in audit or related fields helps ensure that the SAI stays abreast of modern developments in auditing. An SAI should also contribute to the development of the profession, through active participation in events organised, for instance, by INTOSAI and its regional groups and committees. It is also useful for an SAI to participate in and, when appropriate, provide leadership to relevant professional organisations at the national level.

\section{Role of Supporting Functions}

- The organisational structure of an SAI should have adequate support functions, such as IT, training, methodology, finance and administration, human resources and international affairs - depending upon its size, legislation, social, economic and other relevant circumstances - that ensure that the SAI functions effectively, in accordance with its mission.

- Suitable technological and other infrastructures should be in place to support the audit tools and techniques used by audit staff.

- The SAI should have effective arrangements in place to obtain the services of outside experts when needed to carry out audits of an unusual nature, and to ensure that the work of such experts satisfies the quality standards of the SAI.

\section{Types of SAIs}

SAIs differ widely in structure and mode of operations. The two broad types are generally described as "courts" and "offices". Within these categories, however, there is wide variation.

In SAIs of the "court" type, for example, some employ a high-level collegial approach to deciding important issues, with considerable central direction and management of the institution. In these SAIs, the President (or Chair) may have significant influence on the decisions made in this collegial process. Between the members of the court and the individual auditors, there may be several levels of hierarchy or supervision, which are similar in some ways to those of an audit office. The Algemene Rekenkamer (Netherlands Court of Audit) is an example of this structure.

In other audit courts, most decision-making authority is vested in the separate components ("chambers"), which may operate to a great extent independently of each other. Within the separate chambers, there are likely to be few, if any, layers of supervision between the auditors and the decision-making college of the chamber. Audit courts of this type also typically have juridical (judicial) functions, primarily with respect to financial irregularities, as well as the audit responsibilities found in other SAIs. The Cour des Comptes (Court of Accounts) of France is an example of this type of audit court. It is assisted by the "parquet général" (general prosecution), which provides the Court with legal advice, takes part in the quality control process by reviewing audit reports, and in some limited cases acts as public prosecutor. Most of the auditors are magistrates who are sworn in when they enter the Court.

SAIs organised as "offices" are often thought to be a relatively homogeneous group but here, too, labels can be misleading. Such SAIs are generally headed by a single official, typically with the title "Auditor General". ${ }^{2}$ The authority actually exercised by this official, however, can vary widely. In some, virtually all

\footnotetext{
${ }^{2}$ In an important exception to this pattern, the Riksrevisionsverket (National Audit Office) of Sweden has three Auditors General, all of equal status.
} 
major decisions (typically including final approval of an audit report, for example) are made by, or referred to and approved by, the Auditor General. In others, substantial authority may be delegated to subordinate officials. These subordinates may have independent authority to initiate audits and approve issuance of the resulting report. The UK National Audit Office is an example of this type of SAI.

\section{Types of Audits}

Just as there is wide variation in the organisational structure of SAIs, there is a wide range of types of audits those SAIs may perform. It is common to refer to two general types - financial audits and performance audits. In fact, however, there are many varieties of audits, which might be categorised as follows:

- Financial Statement (attestation) Audit: Do the audited statements or reports accurately portray the financial condition and/or activities of the audited entity?

- Regularity Audit: Did the auditee comply with applicable laws and regulations?

- Economy Audit: Do the means chosen represent the most economical use of public funds for the given function or activity?

- Efficiency Audit: Are the results obtained commensurate with the resources employed?

- Effectiveness Audit: Are the results consistent with the objectives of the programme or policy?

- Evaluation of the consistency of the policy: Are the means employed by the policy consistent with the set objectives?

- Evaluation of the impacts of the policy: What are the economic and social impacts of the policy?

- Evaluation of the effectiveness of the policy and analysis of causality: Are the observed results totally or partly due to the policy, or are there other causes?

Each of these different types of audit involves differing methodologies and, as a consequence, different sorts of quality controls and management requirements.

\section{Definitions}

Terminology differs widely among SAIs. For clarity, the following terms are used in this paper:

Quality controls are the procedures by which an SAI seeks to ensure the high quality of its audit and other work.

Quality assurance is the process by which an SAI can ensure that:

- needed controls are in place;

- controls are being properly implemented; and

- potential ways of strengthening or otherwise improving controls are identified. 
Quality management system is a set of coordinated activities to direct and control an SAI with regard to quality and consists of four parts:

- quality controls

- quality assurance

- quality planning to specify quality objectives and related procedures

- quality improvement to achieve ever higher quality work

Audit programme comprises a series of audits that are anticipated to be performed over some specified period of time.

Audit task plan describes the activities to be carried out in connection with a particular audit.

Principal Auditor is the person who is responsible and accountable for the performance of an audit. Depending on the circumstances, this may be an individual who is performing the audit alone, or the leader of one or more teams acting in concert to conduct the audit.

Audit Director is the immediate supervisor of the principal auditor. In a non-hierarchical, decentralised audit court some, but not all, of the functions ascribed to this official may be performed by a senior magistrate ("contre-rapporteur").

Senior manager is a member of the SAI's top management, subordinate to the head of the SAI. In an audit office, this would often be a person with a rank comparable to Assistant Auditor General. In a decentralised audit court, some of the functions ascribed to this official may be performed by a senior magistrate, while others may be performed by the college of the relevant chamber.

\section{Conclusions}

Policies for an effective quality management system may therefore be said to rely on the SAI's quality audit processes and structures as an institution, and on the development of the full potential of auditors as professionals, including their adherence to the SAI's Code of Ethics.

A quality attitude thus needs to be fostered and supported by systematic quality systems and adequate policies, procedures, records, technologies, financial and human resources and structures.

\section{Acknowledgements}

In December 2002, the Presidents of the Supreme Audit Institutions (SAIs) of the Central and Eastern European countries, Cyprus, Malta and Turkey and the European Court of Auditors, at their meeting in Bucharest, adopted a resolution that included the following statement:

"In view of the importance of the theme and increased awareness by an SAI on quality control and post-audit review, it is advisable to explore the feasibility of preparing a comprehensive and detailed Guideline based on the European Implementing Guidelines for the INTOSAI Auditing Standards (in particular on Guideline No. 51, 'Quality Assurance') for discussion among interested parties, including the Contact Committee of the SAIs of EU Member States. The Presidents ask the SAIs of Hungary, Malta and Poland and other interested parties to consider preparing such a guideline with the assistance from all interested SAIs and from SIGMA." 
The Expert Group comprised:

The SAIs of Hungary (Janos Revesz), Malta (Brian Vella) and Poland (Jacek Mazur) as well as the Cour des Comptes of France (Anne-Marie Boutin and Christophe Perron); and SIGMA (Nick Treen and Harry Havens), with appreciated contributions from other SIGMA staff and experts (Bo Sandberg, Joop Vrolijk and Jens Piontek).

The Guidelines prepared by the Expert Group and approved by the SAIs of the EU can be found at

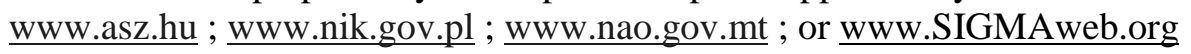

SIGMA would like to sincerely acknowledge the excellent work of the Expert Group and its input into this paper. The work of Harry Havens and Nick Treen in making this paper possible is also acknowledged as well as the expertise of the panel of second readers: Anne-Marie Boutin, Consiellier Maitre from the Cour des Comptes of France; Bo Sandberg, Director from the Riksrevisionen of Sweden; and Detlev Sparberg, formerly Member of the Bundersrechnungshof of Germany and the NATO Board of Audit. 


\section{CHAPTER 2 - QUALITY CONTROL}

\section{Introduction}

Quality control procedures applicable to the audit process itself are a vital element in seeking to ensure high quality in the work of the SAI. Effective quality control procedures - based on international standards and the experience of other countries - are described in this chapter. Establishing such procedures is the first step.

In addition, an SAI must ensure that the procedures are operating effectively. Experience has demonstrated that a particularly effective means of doing so is the use of post-audit quality reviews. This is addressed in Chapter 3.

Many SAIs also have learned from long experience that effective quality control and quality assurance procedures - vital though they are - are only part of an overall strategy for building a fully effective SAI, producing high quality audits and having an appropriate influence on the accountability and effectiveness of state entities. This part of the overall strategy can be described as "managing the institution for quality". Good practices in this broader area are discussed in Chapter 4.

\section{Quality Management in the Audit Process}

The nature and extent of an audit organisation's internal quality control system depends upon factors such as the type of SAI (Court of Audit/Accounts or National Audit Office), size, degree of delegation of decision power, nature of work, type of audit carried out, organisational structure, appropriate cost/benefit considerations, level of staff, and legislation.

\section{Phases of Audit - Planning, Execution, Reporting and Follow-up}

A quality control system should be in force during all stages of an audit.

All persons involved in an audit have a personal responsibility to understand their duties and to ensure that their work complies with standards. This involves all phases of an audit. It is also important that quality control takes place in an atmosphere of openness and trust - an interactive process where subordinates also are encouraged to give feedback to superiors on the way in which the audit is managed and present ideas of possible improvements.

All levels of staff should be assessed on a periodic basis to determine any skills, qualifications and aptitude gaps of the staff. This aspect of managing human resources is discussed more extensively in Chapter 4. During this assessment process one may also find out whether things have gone wrong (and why) during the audit and what corrective action may be taken to rectify these shortcomings in future audits.

\section{Managing the Audit Process - Direction, Supervision, Review}

SAIs should ensure that effective direction, supervision and review are present during all stages of an audit to provide reasonable assurance that work has been performed competently. 
Direction $=$ giving appropriate instruction to the staff to whom work is delegated.

Supervision $=$ monitoring the progress of the audit to ensure that work is being carried out in accordance with the audit task plan and, if necessary, resolving problems that arise during the course of the audit.

Review $=$ assessing the adequacy of audit planning and execution, and of the resulting report.

These matters are discussed more extensively in Annex F, including differences in procedures between hierarchical SAIs and those in which management functions are largely vested in component colleges or chambers.

\section{Implications of Computerisation}

Special attention should be given to the potential advantages and possible problems of computerisation. Auditing requires special skills when the auditee operates in a computerised environment. The auditors in these circumstances must have not only a basic understanding of computers, but must have or quickly acquire knowledge of the systems and programmes used by the auditee. SAIs should provide appropriate training to develop these skills and expert assistance when needed, for example to evaluate IT systems.

At the same time, computerised audit programmes - when properly employed - can greatly increase the efficiency of the audit process. For example, they can make it possible for most or all audit working papers to be captured in electronic form, rather than being manually prepared. Modern audit systems that make extensive use of computers to render the audits largely paperless, including the related working papers, procedures and documentation, contain many built-in controls and safeguards. In such systems all stages of the audit could be managed in an electronic format. Such programmes can also greatly expedite audits, especially those of a repetitive nature.

An automated quality control system may incorporate a strictly defined set of authorization and approval criteria, as well as features that ensure that standard documents and checklists (which may be readily available electronically to all audit team members) are used and completed in all cases.

With such systems, some parts of the work of supervisors and reviewers are electronically supported on a real-time basis. A first draft of some types of audit reports can be generated automatically, following the conclusion of the audit. Ultimately, however, a system, including an IT system, is only as good as what is put into it.

\section{Sources for Quality Control Criteria}

The guidelines set forth in Annex D are recommended to provide a strong foundation for an SAI's quality management system. Other criteria for quality control could be found in a number of sources, such as:

- audit legislation;

- auditing standards (including INTOSAI Auditing Standards, European Implementing Guidelines, IFAC International Standards on Auditing, and the SAI's own standards);

- mission and vision statements of the SAI and other SAI policies;

- SAI regulations, circulars, checklists and guidelines;

- audit manuals. 


\section{Quality in Audit Planning}

An SAI is likely to need a whole range of planning mechanisms. The structure of planning described here was designed for an SAI that is centrally directed. The same needs are likely to be faced by a decentralised SAI, but a different structure may be required. The typical levels of planning for a centrally managed SAI are set forth in the accompanying table.

For all SAIs, the potential audits they might perform far exceed the audit resources that are available, in terms of both the number and the mix of skills of audit staff. These constraints limit the number and the type of audits that the SAI can undertake. Thus, in seeking high levels of quality, the first task of an SAI (or of the component units of a more decentralised SAI) is to use available resources to produce audits of the highest priority possible, with results to be delivered when they are expected to prove most useful.

SAIs also face widely varying situations regarding the extent of discretion that they have in the use of available audit resources. Some SAIs have almost total discretion in selecting which audits to perform and when to perform them. Others are constrained by requirements in law to perform certain audits, such as an

\section{Planning Structure}

Mission and vision statements provide a basis for corporate planning and a general framework for the SAI's operations. To help inculcate the values of the SAI in its staff, it is desirable that the staff, at all levels, participate in the development of the mission and vision statements.

Corporate plans are needed on an SAI-wide basis to set out the overall business strategy for the SAI on a rolling three-year basis (or other reasonable period) so as to lay a foundation for the strategic planning process. The corporate plan should link to the SAI's proposed budget and may be published. In this respect, the SAI will set out its mission and vision as well as overall targets for work.

Strategic plans are needed for the SAI as a whole and for each of its major components, setting out the work required to meet the SAI's aims and duties, how these will be accomplished and with what resources. Overall assessments of audit risk should be evaluated, and the materiality of work areas should be considered in the development of these plans. Responsibilities should be set out in order to measure performance. Typically, this planning process should define the work for the year ahead, subject to revision as circumstances change. This definition of the upcoming year's work should be coupled with a somewhat more tentative forecast of work to be undertaken over at least a one-year period, possibly even for a period covering three or more years. The heads of major SAI components should propose these strategic plans, in line with the SAI's mission and vision statements and corporate targets, for the approval (or modification) of the President (Auditor General).

Operational plans (annual or multi-year audit programmes and individual audit task plans) are needed for jobs and detailed audit. These plans may be supported by resource management and time recording systems to provide data to enable monitoring, management and accountability for the work. Operational planning also covers budgetary plans, preliminary investigative plans, feasibility studies and pre-studies.

Appropriate information systems will be needed to support the planning framework and other business information needs.

Internal follow-up and results analysis routines are important tools for the SAI to assess and track the impact of their work. The information they provide should feed into the various planning processes. 
annual audit of the execution of the state budget, with results to be delivered by a specified date. Such constraints may consume a substantial portion of available audit resources, at least during certain periods of the year. Still other SAIs are required to respond to requests for audits from parliament, and the SAI may or may not be able to influence the scope of these audits. Nevertheless, all SAIs need to have an effective process, by which they decide how to use their resources to best effect.

\section{Participants}

The audit planning process should ideally be based upon consultation among various SAI personnel, depending upon the phase of planning that is being considered. In a centrally managed SAI, annual and/or multi-year audit programme decisions would typically involve the head of the SAI, who would give final approval, as well as others in the management hierarchy. In an audit court that employs centralised collegial decision processes, a comparable approach may be used, with final decisions being made by the collegium.

In other SAIs, with a more decentralised approach to management, authority for these decisions may reside in, or be delegated to, component parts of the SAI. In this case, the separate decisions may, or may not, be consolidated into a single programme representing the anticipated work of the SAI as a whole.

The audit task plan for a specific audit is typically developed by the principal auditor and the audit team under the supervision of the audit director, as appropriate. This sharing of responsibility and experiences should help ensure that audit programmes and task plans are realistic and achievable.

\section{Annual Audit Programme}

Most SAIs have a planning approach that operates at several levels. One common approach is the development of an annual audit programme ${ }^{3}$, which typically entails consideration of a wide range of possible audits (sometimes including potential audits suggested by audit staff). Various attributes of the possible audits are then examined, and subsequently a decision is reached as to which audits have highest priority, given the constraints faced by the SAI.

In developing an annual audit programme, it is often helpful to do so in the context of a longer-term perspective. For example, an SAI might develop a tentative list of audits that it believes should be performed over, say, the next five years. That tentative list would then be re-examined, revised and extended at regular intervals, perhaps annually. This allows the SAI to select audits for one year while remaining aware of the audit work that is anticipated in subsequent periods.

The procedures for deciding the annual audit programme, or other ways of deciding the scope and timing of specific audits, will differ from one SAI to another. Regardless of the process used to reach these decisions in a particular SAI, the considerations that should underlie them remain the same. Thus, even if the process is highly decentralised, with little or no central direction, the organisation - or its decisionmaking components - should seek to take a similar approach, with a similar consideration of the relevant factors throughout the SAI. These factors should be fully documented, particularly discussions and decisions on audit risk, irrespective of the management process that is consistently applied.

\footnotetext{
${ }^{3}$ In this document, the term "audit programme" describes the series of audits that are anticipated to be performed over a specified period of time. The term "audit task plan" describes the activities to be carried out in connection with a particular audit. See the definitions at the end of Chapter 1.
} 
SAIs should also recognize that the audit programme cannot be static. Circumstances change and priorities among potential audit subjects change with them. New problems and new issues arise, sometimes of an urgent nature, and the SAI must be prepared to adjust its work programme to meet those needs. Thus, from time to time, some programmed audits may need to be replaced by others in response to these changing circumstances.

\section{Audit Task Plan}

The preparation of an audit task plan is a vital phase in the audit process. Auditing involves the collection and analysis of data sufficient to reach valid conclusions. The resources available for that process are always limited. Development of the audit plan is the vehicle for reconciling the work to be done with the resources available for accomplishing it. A good audit plan is one which, if implemented properly, has a high probability of accomplishing the audit objective within the limits of the available resources and with the least possible application of resources to tasks that turn out to have been unnecessary.

The preparation of an audit task plan should take into account risk and materiality, based on an understanding of the auditee and its organisational structure, programmes and activities, and the IT environment in which it functions. The plan should set out how and when the audit will be conducted and

\section{Typical Contents of an Audit Task Plan}

The audit task plan should normally address the following matters:

1. Legal framework for the audit

2. Brief description of the activity, programme or body to be audited, including a summary of the results

of previous audits and their impact

3. Reasons for the audit

4. Factors affecting the audit, including those determining materiality thresholds

5. Risk assessment

6. Audit objectives, scope and approach (evidence to be obtained, when and how):

* materiality thresholds

* systems to be evaluated and tested

* methodologies planned to be used

* sampling strategies

* anticipated sample sizes

* reliance on other auditors and/or experts

* special problems that are foreseen

7. Resources required:

* specialist staff (who and when)

* external experts (who and when)

* travel requirements

* time and cost budgets

8. Estimated fee to be charged for the audit, if appropriate

9. Audit entity liaison responsibilities

10. Audit timetable, including estimated date of delivery of draft report

11. Form, content and users of final audit product. 
how sufficient appropriate audit evidence is obtained to support an audit opinion (financial audit) or audit findings, conclusions and recommendations (performance audit). While the basic elements of audit plans are likely to be similar, the actual contents will differ widely depending on the type of audit (financial, regularity or performance), the audit objective(s) and the auditee.

Substantial differences will be found even with a single type of audit. For example, in an audit to certify the financial statements of an entity that is believed to have reasonably good accounting systems, the methodology is likely to emphasise testing the systems and examining the adequacy of management controls. If the accounting systems are computerised, the plan should recognize the need for the team to include staff with the requisite IT skills and computer resources. On the other hand, if the auditor has reason to doubt the soundness of the systems and/or the adequacy of the controls, the plan should recognize the need for the more labour-intensive task of sampling and testing a substantially larger number of individual transactions.

\section{Elements of Quality in Audit Task Planning}

An audit task plan of high quality should reflect a number of elements, including the following:

- The audit objective should be clearly established.

- The intended methodology should be specified.

- Materiality thresholds should be specified.

- The audit risks should be assessed and described.

- The timetable for the audit should be spelled out, along with the date on which the draft report will be ready for internal consideration.

- The financial and human resources required for the audit (such as audit staff, specialist staff and experts required, training, travel arrangements, time and cost budgets) should be assessed and set forth in the plan. The allocation of available resources should be based on the priorities of the SAI.

- Follow-up on issues raised in previous audits should be clearly defined. Permanent audit files should clearly indicate which previous audit issues and recommendations need to be followed up.

- Roles and responsibilities of staff, including any specialists and experts, should be clearly defined.

- Audit steps and testing procedures should be clearly defined and assigned to specific individuals.

- Procedures for documenting audit steps and tests and for updating permanent audit files should be specified in the working papers.

During the audit task planning phase, the principal auditor should do the following, sharing the results with other members of the audit team:

- obtain a comprehensive understanding of the legal framework for the audit, taking into account any legislative requirements and changes;

- obtain a sufficient understanding of the activity, programme or body to be audited;

- establish appropriate liaison with the auditee with respect to the timing, scope and approach of the audit.

As the audit moves into the execution phase, the principal auditor should ensure that planning assumptions remain appropriate, taking into account any significant events occurring after approval of the plan. 
Those preparing an audit task plan should consider the matters discussed in the accompanying tables, Typical Contents of an Audit Task Plan and Elements of Quality in Audit Task Planning.

It has often proven valuable to have the proposed audit task plan reviewed by an experienced auditor who is outside the audit team. Such reviews may raise issues that were not considered by the originator of the plan and that suggest the need to modify the plan in material ways. In an audit office with a hierarchical structure, such a review is typically required by office policy and is usually carried out by one or more supervisory levels above the principal auditor. In a more decentralised SAI, such as some audit courts, the review may be performed on a cooperative basis by a peer of the principal auditor or, if requested, by the responsible senior magistrate (contre-rapporteur).

Those planning financial statement (attestation) audits are advised to consider the standards of the International Federation of Accountants (IFAC).

Among performance audits, the number and complexity of planning issues can be even greater. The methodology for assessing the operating efficiency of an entity will be quite different from the methodology that attempts to measure the effectiveness of a programme in achieving its stated objectives. These two kinds of audits involve collecting and analysing different kinds of data from different sources. In view of the potential difficulty of collecting data needed for valid conclusions in some kinds of performance audits, the plan may need to include a pre-test of the methodology to determine its feasibility. Another frequently useful approach is to perform a pre-study of the potential area of audit to determine the likely usefulness of a full audit and to select an appropriate methodology.

A different sort of issue can arise in a performance audit if the methodology relies on the use of data from administrative records, as many do. In that situation, the plan should include provisions for assessing the validity of that data. This may involve audit steps (testing systems and controls) that are similar in some respects to those used in a financial statement audit.

\section{Typical Methodologies for Carrying out Audit Tasks}

The fieldwork should be performed in accordance with the approved audit task plan and should obtain sufficient appropriate evidence to determine with reasonable confidence whether or not financial statements are free from material misstatement and irregularity - in the case of an attestation audit - or that facts relating to performance audits are scientifically and/or fairly determined. See the accompanying table, based on the European Implementing Guidelines.

The choice of methodology from among the various available methodologies and the way in which the methodology is to be carried out should be carefully considered during the task planning phase of the audit.

\section{Requisites and Measures to ensure Quality Control}

The audit task plan is divided into a number of detailed tasks, which are assigned to individual team members. To ensure quality control during the planning process, measures could include direction, supervision and review procedures to ensure that the audit task plan is adequately prepared. Primary measures may include a management policy for the use of standard layout and structure of documents following the requirements of International Auditing Standards (INTOSAI and IFAC), and the approval of a planning checklist.

The audit director should provide written approval of any changes in audit planning tasks. Changes that substantially affect the overall audit plan - with regard to objectives of audit, timing, and human and financial resources required - should be endorsed by the responsible senior manager. 


\section{Methodological Issues Addressed in the European Implementing Guidelines}

1. Sources and methods of obtaining audit evidence

- Sources

- Methods

- Nature

2. Audit approach

- Objectives

- Testing

3. Study and examination of internal control and tests of controls

4. Information systems

- General installation controls

- Application audits

5. Audit sampling

6. Analytical procedures

- Trend analysis

- Ratio Analysis

- Predictive analysis

7. Using the work of other auditors and experts

8. Documentation

9. Performance audit methodology

- Data gathering techniques

- Information analysis techniques

Audit planning should also provide for monitoring of the job by the audit director with respect to planned versus actual time spent on each job, based on job sheets filled in by each auditor. Monitoring costs is important in an assessment of whether an audit is developing well or not.

An independent review of audit proposals, programmes and task plans by peers or other units within the SAI may also be a useful method of undertaking a quality review of the planning process.

\section{Quality in Audit Execution}

Audit execution refers to the phase of the audit during which data is gathered for the purpose of rendering an opinion or providing findings, conclusions and recommendations with regard to the object of the audit. It is essential that the audit proceed in accordance with the audit task plan, although that plan may need to be modified if circumstances render the original plan inappropriate or inadequate.

\section{Participants}

The main participants in this phase of the audit in a centrally managed SAI are typically the responsible senior manager, the audit director, the principal auditor and team members, if any. The audit director and principal auditor carry out duties of a management nature (direction and review). The principal auditor would also carry out quality control of a supervisory nature with regard to the team members. 


\section{Elements of Quality in Audit Execution}

The responsibility for quality during the execution phase of an audit falls primarily on the principal auditor. To meet this responsibility, the principal auditor, together with an eventual audit director or other supervisor, must ensure that:

- members of the audit team understand the audit task plan and the tasks assigned to them, that they have the skills required to carry out the assigned tasks, and that there are no conflicts of interest or other factors that would impede any team member from carrying out the assigned tasks in a competent and objective manner;

- members of the audit team are appropriately supervised in carrying out assigned tasks;

- the audit progresses in accordance with the audit task plan;

- the planned audit approach remains appropriate in light of information gathered in the audit or that appropriate changes are made;

- changes in methodologies or other elements of the audit task plan are approved by the principal auditor and, if appropriate, by other officials of the SAI;

- appropriate assistance is sought in the event that unforeseen problems or issues arise during the course of the audit;

- audit documentation is properly kept and is easily traceable to audit tests and findings;

- audit evidence procedures are properly followed;

- internal control systems of the auditee, including controls of an IT nature, are properly documented, evaluated and tested;

- proper sampling, analytical procedures, data gathering techniques and techniques for information analysis are used, where appropriate;

- working papers include relevant, reliable and sufficient evidence supporting all conclusions, recommendations and opinions;

- all results of audit testing and findings are properly documented in the audit working papers, the results are properly reviewed, and such reviews are also documented;

- audit findings are described objectively, truthfully, precisely, completely and comprehensively, with emphasis on materiality and conciseness. Problems should be documented in manual or electronic form and, if necessary, subsequently resolved with more senior auditors.

In a decentralised audit court, participants in the execution phase may be limited to the principal auditor and the audit team, with a senior magistrate or contre-rapporteur in a reviewing role and available to provide advice and assistance, if requested.

\section{Roles and Responsibilities}

It is useful, before starting the actual fieldwork of the audit, for the principal auditor to review carefully the audit task plan to ensure that it can be properly implemented. If he or she is functioning as the leader of an audit team, this review should be performed in conjunction with the members of the team, to ensure that all understand the audit plan as a whole and their roles, and to give them an opportunity to raise any concerns they may have. Issues that are raised and resolved at this stage can help avoid problems and delays later on in the audit. 
During the course of an audit, the principal auditor should supervise the work of the team members, if any, to ensure that work is being carried out appropriately, in accordance with the plan. The extent and nature of this role will depend upon such factors as the number of persons in the audit assignment, their experience, expertise, qualifications and aptitude. It is not uncommon, during the course of an audit, for members of an audit team to encounter unanticipated difficulties, the resolution of which is beyond their capabilities. In these situations, team members should be encouraged to seek assistance from more experienced auditors and/or the principal auditor.

If a problem is encountered that requires skills that team members do not possess, the principal auditor should seek assistance from relevant experts. For example, if legal issues arise, it may be appropriate for the principal auditor to seek advice from legal experts within or outside the SAI. Difficult analytical problems may necessitate the involvement of qualified statisticians, economists, or other experts.

In implementing the audit plan, it is helpful if all team members prepare, on a daily or otherwise regular basis, sufficiently detailed job/time reports. Such reports can help ensure that work is carried out within the agreed schedule and staff days allocated for the audit.

Supervisory duties can become especially challenging in an audit involving multiple groups of auditors in several locations. In this situation, there may actually be several audit teams at work simultaneously, each being led by a "team leader". The principal auditor is responsible for coordinating the work of the various teams to ensure that the results come together and for supervising, as necessary, the leaders of the various teams.

In hierarchical audit offices and centrally managed audit courts, it is common to have several layers of supervision above the principal auditor. In these organisations, at least one of the supervisory levels (the audit director) is typically expected to remain in touch with the principal auditor and to periodically review the progress of the audit, identifying any problems that may have arisen. This supervisor is normally responsible for approving any substantial changes in the audit task plan and for obtaining any specialised assistance that the principal auditor may require.

In more decentralised audit courts, there may be few, if any, supervisory levels above the principal auditor. A senior magistrate or contre-rapporteur may be available to provide advice, if requested, but typically this person has no authority to direct the principal auditor in the execution of the audit. This situation places even greater responsibility on the principal auditor for ensuring successful completion of the audit.

Upon completion of audit testing, the principal auditor - and his/her supervisors, if any - should review all aspects of the audit tasks performed during the audit, including tests carried out, findings and working papers, and documentation of reviews. It is potentially helpful, in this review process, to identify changes and improvements necessary for future audits.

\section{Requisites and Measures to ensure Quality Control in Execution/Fieldwork}

The fieldwork, which would have been appropriately planned during the planning stage, should be assigned to individual team members. To ensure quality control during the execution/fieldwork process, measures could include direction, supervision and review procedures to ensure that team members understand their assigned tasks and that the chosen audit methodologies are adequately carried out.

Primary measures may include an SAI management policy for the use of audit programmes and questionnaires, setting out the work to be performed and the evidence to be obtained. Another policy should include clear guidance regarding the preparation of audit files, setting out and recording the work 
done and the results obtained, as well as the use of pre-prepared worksheets, such as for the audit of systems and controls.

The following discussion describes the roles that may be assigned in a centrally managed SAI with a hierarchical structure. In a decentralised audit court, most of these responsibilities would typically fall on the principal auditor.

Primary responsibility for quality during the execution phase lies with the principal auditor, who should seek to satisfy the criteria set forth in the accompanying table, Elements of Quality in Audit Execution. In addition, however, in their supervisory roles, the audit director and responsible senior manager should also review progress from time to time to ensure that proper procedures are being followed in satisfying the criteria in the Elements of Quality.

As a general rule in hierarchical audit offices, each team member should be supervised by his/her immediate superior. Team members should be made aware that they must take due care in their fieldwork and that they will be held accountable for ensuring that work is properly carried out.

Auditors, at whatever level in the organisational structure, should be encouraged to point out possible shortcomings in the audit task plan and/or the quality control measures being applied in the audit and to provide their views to superiors on any areas relevant to the audit work. Feedback between fieldwork auditors and their superiors helps communications and relations between all levels of staff and increases understanding of audit tasks and related problems by all concerned.

\section{Quality in Audit Reporting}

Audit reporting refers to the phase of the audit in which the data and evidence that have been gathered are analysed, conclusions are reached, and results are set out in the form of a written document. Depending on the nature and objectives of the audit, the resulting product may be a relatively short statement attesting to the audited financial statements or reports or a more lengthy analysis of the economy, efficiency or effectiveness of an entity's policies, programmes and operations.

\section{Participants}

In a centralised audit office, the main participants in this phase are the principal auditor and the audit team, who prepare the draft report; the responsible senior manager and the audit director, who review the draft report; and the head of the SAI and/or his deputy, who have to approve the report. Many SAIs also require review of the draft report by another individual or group, independent of the regular hierarchy, before the report is submitted to top management for final approval.

In a court of audit, the participants in this reporting phase will depend on the structure of the court. In some cases, the procedures may be similar to those of an audit office. In others, more collegial arrangements are involved in preparing and approving the report. In that case, primary responsibility rests with the principal auditor, with a senior magistrate or contre-rapporteur and legal staff (avocat général) in the reviewing role and final decisions being made by the college of the relevant chamber.

In either case, a further participant in this phase is the auditee, through the contradiction process. 


\section{Roles and Responsibilities}

In preparing the draft report, the principal auditor and the audit team, under the supervision of the audit director, should give special attention to the matters listed in the accompanying tables, Elements of Quality in Audit Reporting and Typical Contents of an Audit Report.

After the principal auditor has completed a draft of the audit report, it is very useful to have the draft report reviewed by another auditor of appropriate experience, who may note gaps or other shortcomings in the report that will need to be corrected. In an audit office, this first reviewer is typically the audit director or another official who is immediately superior in the hierarchy to the principal auditor. In an audit court, this reviewer may be a senior auditor (contre-rapporteur).

It is advisable that this review be coupled with or followed by further reviews of the draft report at higher levels or other parts of the organisation, especially if the subject of the report is sensitive or the material is unusually complex. For example, if the audit raises significant legal issues, the report should be referred to the SAI's legal staff or outside legal advisers. In a performance audit involving complex methodologies, internal or external experts may be needed to ensure that the data and analysis support the conclusions. The results of all reviews should be documented and retained in the audit working papers. In some courts of audit, the report is reviewed by the legal staff (parquet).

\section{Elements of Quality in Audit Reporting}

The quality of an audit report should be judged in several dimensions. Following are some of the key elements of a high quality audit report:

- The structure of the report is in line with applicable SAI policies and standards.

- The report is concise, clear, timely, precise, simple, and objective. Facts are presented in neutral terms. The report is constructive and presents both positive and negative conclusions.

- All audit findings have been evaluated as to their materiality, legality and factual evidence.

- There is documentary evidence in support of all opinions, findings, conclusions and recommendations. There is a clear audit trail for audit steps, findings, conclusions and recommendations, prepared by the principal auditor and his assistants and fully cross-referenced to the working papers.

- All relevant material findings have been included. Any conflicting evidence has been carefully assessed and a valid explanation provided for disregarding it.

- Relevant and material events subsequent to the audit have been taken into account, to the extent that the principal auditor was, or should have been, aware of them.

- Written representations have been made by management of the auditee, particularly in instances where material audit findings could not otherwise be confirmed.

- Applicable SAI procedures have been followed with regard to any serious irregularities and/or fraud discovered in the audit.

- The proposed report has been reviewed within the SAI in accordance with SAI policies, including review by legal and other experts, as warranted.

- The auditee has been provided an opportunity to review and comment on the draft report. Views of the auditee are mentioned in the report, if appropriate. Any divergences of opinion with the auditee or questions of fact challenged by the auditee have been discussed and resolved, if possible, during an exit conference or contradictory procedure.

- Issuance of the final report has been approved in accordance with SAI policies.

- Time limits have been respected. 


\section{Typical Contents of an Audit Report}

Reports, for both regularity and performance audits, should be in standard format. The European Implementing Guidelines require the auditor to give specific attention to the following:

- Title

- Signature and date

- Objectives and scope

- Completeness (areas not covered by audit should be specified)

- Addressee

- Identification of subject matters

- Legal basis

- Compliance with standards

- Timeliness

\section{Financial Statement (Attestation) Audit Reports}

An audit opinion for a financial statement (attestation) audit is normally in standard format, relating to the financial statement as a whole. The wording of the audit opinion will be influenced by the legal framework for the audit, but the content of the opinion will need to indicate unambiguously whether it is unqualified or qualified.

In terms of ISA 700 of the IFAC and Section 4.0.10 of the INTOSAI Code of Ethics and Auditing Standards (INTOSAI Standards), an Unqualified Opinion is given when the auditor is satisfied in all material respects that:

(a) the financial statements have been prepared using acceptable accounting bases and policies which have been consistently applied;

(b) the statements comply with statutory requirements and relevant regulations;

(c) the view presented by the financial statements is consistent with the auditor's knowledge of the audited entity; and

(d) there is adequate disclosure of all material matters relevant to the financial statements.

If an unusual or important matter ("Emphasis of Matter") needs to be included in the Audit Report to enable the reader to correctly understand the Financial Statements, this should be contained in a separate paragraph from the audit opinion in order not to give the impression that the Audit Report is being qualified (Section 4.0.11 of the Standards).

If the auditor is unable to provide an Unqualified Opinion, the auditor usually provides one of the following audit opinions (Sections 4.0.13-4.0.15 of the INTOSAI Standards and ISA 700):

A Qualified Opinion if there is limitation on the scope of the auditors' examination or if the auditor disagrees with the treatment or disclosure of one or more items in the Financial Statements which are material but not fundamental in understanding the Financial Statements; 
An Adverse Opinion if the auditor is unable to form an unqualified opinion on the Financial Statements as a whole due to disagreement that is material and fundamental, rendering the Financial Statements seriously misleading;

A Disclaimer of Opinion if the auditor has not been able to obtain sufficient evidence to support and express an opinion on the Financial Statements as a whole due to uncertainty or scope restriction that is material and fundamental.

It is customary for a SAI to provide a detailed report amplifying the opinion in circumstances in which it has been unable to give an Unqualified Opinion (Section 4.0.16 of the INTOSAI Standards).

\section{Performance Audit Reports}

Performance audit reports normally include the following elements (7.2 of Guideline No. 41 of the European Implementing Guidelines):

- Summary of the environment within which the activity subject to audit takes place;

- Objectives of the audit;

- Summary of audit methodologies used for collecting and analysing data and indication of sources of data;

- Explanation of criteria, such as benchmarks, used to interpret findings;

- Findings that are considered material to the intended users of the report;

- Conclusions relating to audit objectives; and

- Recommendations.

Management of the audited body should also be given the opportunity to comment on the draft report and have its comments included, where deemed appropriate.

The Audit Opinion (Findings, Conclusions and Recommendations in Performance Audit Reports) presents either a favourable opinion or highlights all significant instances of non-compliance and criticisms that are pertinent to the objectives of the audit. It also provides independent information on whether economy, efficiency and effectiveness have been achieved or how they can be improved upon.

After completing the drafting and internal review processes, the report should be submitted to the auditee(s) for review, contradiction and comment. This gives the auditee an opportunity to challenge assertions of fact with which it disagrees, or to offer alternative, more favourable interpretations of data. If an auditee has a valid basis for any such disagreements, it is better to resolve them at this stage, if possible, rather than having them become the subject of a public controversy.

To avoid unnecessary delay in the issuance of the final report, it is common practice to allow a specific period of time for the auditee(s) to submit any comments. The allowed time for comment varies from one SAI to another, but it is not uncommon to restrict the comment period to 30 or 45 days, with extensions being allowed when deemed justified. The principal auditor and audit team should give fair consideration 
to issues raised by the auditee in the contradictory procedure. Every effort should be made to resolve disagreements and to adjust the report in response to valid points made by the auditee(s). In some SAIs, auditee comments in the contradictory procedure must be referred to higher levels in the hierarchy for resolution.

It is common practice in many SAIs to include in the final audit report the comments received in the contradictory procedure, together with the SAI's analysis of - and action on - those comments.

When the contradictory procedure has been completed, the next step is to publish the final report. The process for making this decision to publish differs among SAIs. In a hierarchical audit office, it is common for this decision to be made by the auditor general or another senior official of the office. In an audit court, authority for the final decision may rest with the chamber that performed the audit, or it may be referred to a collegium of top officials of the court, depending on the structure of the court.

In a decentralised audit court, the contradiction process may involve a formal proceeding before the college of the chamber. The draft report and the results of the reviews, including the contradiction process, are then considered by the college of the relevant chamber, which makes the final decision to issue the report. Here too, the actions and results should be well documented.

\section{Requisites and Measures to Control Quality in Reporting}

The need to prepare a report should be appropriately taken into account in the task planning and execution stages of an audit. This function should be mainly assigned to the principal auditor, together with the audit director. Quality control measures during the reporting phase include direction, supervision and review procedures to ensure that the contents of the audit reports are properly prepared in terms of SAI legislation, practices and procedures and that the elements that ensure a good quality report, mentioned in the accompanying tables, Elements of Quality in Audit Reporting and Typical Contents of an Audit Report, are taken into account.

Once the audit fieldwork is complete and approved, the findings may be presented in an interim report, prepared by the principal auditor, with assistance from audit team members, and reviewed by the audit director, which would be transmitted to the audited bodies for review and contradiction. The purpose is to check the accuracy of the audit findings prior to continuing with the drafting of the report.

Once the reply to this interim report has been received and considered, the audit team drafts the final audit report, under supervision of the audit director.

The audit director - and any subsequent reviewers - should carefully assess the extent to which the report satisfies the criteria presented in the accompanying tables, Elements of Quality in Audit Reporting and Typical Contents of an Audit Report.

Some SAIs find it useful to have a system wherein the audit report is submitted to a specific section within the SAI, independent of the audit team, that reviews the audit report for technical adequacy and compliance with SAI policies, prior to submitting it to the responsible senior manager for final review. This step may, alternatively, be carried out following the review by the responsible senior manager, but prior to submitting it to the head of the SAI and/or his Deputy for approval.

Some SAIs follow the practice of having the report reviewed for adequacy by a second senior manager, who is independent of the audit team. This practice, first seen in some private auditing firms where it is called a "second partner review", provides an additional check on the quality of the audit work. 
The report and the audit file are then passed on to the responsible senior manager for final review. He/she reviews the report and ensures that the audit director has adequately performed his/her own review. In the event that sensitive issues of a legal nature arise (findings of an apparently significant violation of law, for instance, or matters relating to data security), the responsible SAI senior manager should seek legal advice. This senior manager then approves the report or amends it as necessary.

A further step may be the editing of the report by an editor, from inside or outside the SAI, prior to submission of the report to the head of the SAI and/or his deputy. Such an editorial review can help to ensure the clarity of the text. Another step could be to have the audit report reviewed by a person, from inside or outside the SAI, who has no knowledge of the subject of the audit report in hand (other than that of a layman). This would help ensure that the report is understandable to persons not involved in the audit, such as members of parliament and the general public.

The amended final report is then referred to the head of the SAI and/or his deputy, who signs the report following any amendments he/she may wish to make.

As noted earlier, the arrangements in some courts of audit are considerably different, but with the same basic purposes.

\section{Audit Follow-up}

Audit follow-up has two purposes. One is to encourage an appropriate response to audit findings on the part of the auditee or other responsible entities. If an auditee has acted to overcome problems found during an audit, it is appropriate for the SAI to recognize that fact. If, on the other hand, the auditee has not acted in response to the audit, it is also appropriate for the SAI to disclose that the problem(s) persist.

The other purpose of audit follow-up is to lay the foundation for future audit work. If previously disclosed problems are believed to have been resolved, subsequent audit work in that area may require only minimal testing to confirm that the problem no longer persists. If the problem has not been overcome, further audit work may be warranted to confirm the nature and significance of the problem, in the hope of evoking a more appropriate response from the auditee.

Actions required for effective follow-up will vary widely from one situation to another. In some circumstances, a simple inquiry directed to the managers of the auditee may be sufficient. In other cases, more substantive examination and testing will be required. The choice depends on the nature of the issue.

SAIs pursue their audit follow-up responsibilities in various ways. In some situations, follow-up may be a separate phase of the audit process. This approach would be appropriate if the auditee is unlikely to be subject to further audits in the near future. In other cases, follow-up on the results of previous audits may be incorporated into the plan for a subsequent audit. This approach would be appropriate if the entity is subject to recurring audits on a relatively frequent basis. 


\section{CHAPTER 3 - POST-AUDIT QUALITY ASSURANCE}

\section{General}

Each organisation conducting audits should have an appropriate internal quality control system in place during all stages of an audit, as was discussed in the previous chapter. Apart from such a system, the SAI should undertake further internal or external post-audit quality assurance reviews. These "cold" reviews help establish whether systems are working effectively, and usually also lead to recommendations for improvement of future audits.

Paragraph 2.1.25 of the INTOSAI Auditing Standards states that:

"The SAI should adopt policies and procedures to review the efficiency and effectiveness of the SAI's internal standards and procedures."

This standard is further amplified by paragraph 2.1.27, which specifies that:

"They should establish systems and procedures to:

(a) confirm that integral quality assurance processes have operated satisfactorily;

(b) ensure the quality of the audit report and secure improvements; and

(c) avoid repetition of weaknesses."

And paragraph 2.1.28, according to which:

"... it is desirable for SAIs to establish their own quality assurance arrangements. That is, planning, conduct and reporting in relation to a sample of audits may be reviewed in depth by suitably qualified SAI personnel not involved in those audits, with consultation with the relevant audit line management regarding the outcome of the internal quality assurance arrangements and periodic reporting to the SAI's top management."

And paragraph 2.1.29, which states that:

"It is appropriate for SAIs to institute their own internal audit function with a wide charter to assist the SAI to achieve effective management of its own operations and sustain the quality of its performance."

These standards are further elaborated in European Implementing Guideline no. 51, which states that quality assurance is a two-stage process and goes on to say:

"At the first level the SAI must, as a matter of policy, define and decide upon the appropriate standards and level of quality for its outputs and then establish comprehensive procedures designed to ensure that this level of quality is attained. These policies and procedures should be established by reference to the global objectives of the SAI, which will normally reflect the legal requirements and socio-political expectations that the SAI faces." 
Guideline no. 51 goes on to specify that:

"Whilst the policies and procedures outlined above provide the basis for achieving the desired level of quality, and thus adherence with the INTOSAI Auditing Standards, it is not usually sufficient just to put these policies and procedures in place. It is usually also necessary to obtain assurance that they are being adhered to and that they are achieving their objective."

\section{Types of Post-Audit (“Cold”) Quality Reviews}

Post-audit quality reviews may be in the form of:

- Internal Evaluations: These evaluations are carried out by the SAI's own auditors or other experts who are independent from the audit in question. The experts would look into the presentation and format, technical content and quality of audit, initial impacts and overall assessment.

- External Evaluations: These evaluations involve external experts - from academic or other professional bodies, other SAIs, or other external organisations - who may be engaged by the SAI to examine specific audits.

- Feedback from Auditees: Comments on the conduct of the audit and report are requested from the auditee in order to have the auditee's perspective as to how well managed the audit was and as to whether any "value-added" was achieved, for instance through the SAI's recommendations.

- Team Review: The team conducting the audit discuss what lessons have been learned, what worked well and why, what was less successful and why, and what lessons could be drawn for the future.

An important type of external review is the peer review, which is usually only carried out at an interval of several years. In this type of review, the audit institution's organisational structure and working methods are assessed and reported upon by senior members of another SAI (equivalent), who would also suggest measures for improvement. The peer reviews organised for EU candidate countries by SIGMA, which engages senior auditors from EU Member State SAIs for the task, belong in this category, although the focus is typically much broader than quality controls.

Indirect "cold" reviews may include surveys of interested parties, feedback from parliamentary committees or parliamentarians having reviewed the audit reports, comments on reports from the media, and any other forms of expression on the audit and audit report that are made following the completion of the relevant audit.

\section{Objectives of Post-Audit Reviews}

Effective quality control assessment procedures necessarily involve the examination of specific audits. However, the purpose of the review is not to analyse in detail those specific audits. Rather, it is to determine what controls were intended to apply to those audits, how those controls were implemented, whether any gaps in the controls need to be filled, and other ways of improving the efficiency and/or effectiveness of the control system.

For those performing internal or external reviews of audits and related reports to assess the adequacy of an SAI's quality controls, the checklists appearing in Annex F may be helpful. Other issues regarding postaudit reviews are discussed in Annex G. 
Some SAIs have found it useful to assess on their own the overall impact and quality of their reports and audit work, or seek the views of auditees regarding the quality of the SAI's audit reports. The latter can provide helpful insights; this is especially useful in cases where the SAI and the auditee have established a relationship of mutual respect.

\section{Internal Assessments}

The appropriate ways of assessing quality controls using resources internal to the SAI will depend significantly on the structure of the SAI. In an audit office with a relatively strong central management, one common approach is the establishment of a separate office, independent of the audit units and reporting directly to the Auditor General. This office may select a sample of audits that is representative of the work of the office (or of one of its component units), examining it in detail and reporting the results, along with recommendations for improvement, to the office's top management. A comparable approach might be appropriate in an audit court where overall management responsibility is vested in a collegium.

In a more decentralised audit court, where management authority is vested in the component units or chambers, a markedly different approach is likely to be needed. One possible approach would be for each chamber to seek the assistance of another chamber in performing the needed reviews. The work of the second chamber would be in the nature of advice to the chamber being reviewed.

\section{External Assessments}

Internal assessment procedures can be usefully augmented by assessments performed by external experts who are independent of the SAI. One approach is to invite experts from the private sector or the academic community to review relevant parts of the SAI's work. For example, a respected private audit firm might be asked to review a sample of the SAI's financial statement (attestation) audits. In similar fashion, a consulting firm or respected academics could be asked to review selected performance audits that had employed methodologies with which they were familiar. This approach might be applied by each of the chambers of a decentralised audit court, as well as by other, more centrally directed SAIs.

Another approach to external assessment is increasingly common. This involves one SAI asking another SAI to perform an assessment of its audit work and quality controls. When this approach - called a "peer review" - is used, it is important that the reviewing SAI have experience in the type of work performed by the requesting SAI. It is also helpful if the two SAIs have similar structures. It could be difficult, for example, for a decentralised audit court to readily adopt control procedures suggested by a centrally managed audit office, based on its own practices and experience.

A peer review focusing on quality issues should determine whether, during the period under review, the SAI's internal quality control system was adequate and whether quality control policies and procedures were being complied with to provide the SAI with reasonable assurance of conforming to applicable professional standards.

A variation of the SAI-to-SAI assessment approach is the peer review process organised and supported by SIGMA's SAI experts. In this process, SIGMA assembles a team of experienced senior auditors from various SAIs, who perform the review of an SAI. In principle, such a review could focus on the quality of an SAI's work and its quality controls. In practice, however, these reviews have had a broader scope, encompassing, for example, the legal foundation and independence of the SAI and its overall management. The intention of this type of peer assistance is to focus on motivating management to effect beneficial change by producing recommendations, which have been produced together by SIGMA peers and the peers in the SAI, for improvement. 
Procedures should be established by the SAI, in collaboration with the post-audit reviewer, to determine the nature, extent, frequency and timing of post-audit reviews. These agreed procedures should ensure that reviewers have reasonable access to all documents needed for the review and should specify the expected time and cost of the review.

\section{Conclusions}

Post-audit reviews, if carried out properly, constitute an important type of review, as they independently and objectively ascertain whether an SAI's quality control system is efficient and really operates as intended.

It is desirable to prepare annual internal reports on post-audit quality reviews, summing up general findings and recommendations, to be presented to and discussed by SAI audit staff. These reports would be useful in objectively identifying shortcomings and improvements required and in stimulating suitable corrective measures.

In this connection, it is vital that the SAI leadership, including the head of the SAI, be seen to play an active role with respect to the quality assurance process. Such active involvement in demanding the required post-audit reviews and taking responsibility for ensuring proper responses - including the decision to take any needed corrective action - is an essential element in establishing a quality-oriented environment in the SAI. 


\section{CHAPTER 4 - INSTITUTIONAL MANAGEMENT}

\section{Introduction}

Quality controls are essential for ensuring that the planning, execution and reporting phases of the audit process are carried out properly. Post-audit quality reviews assess whether those controls are operating effectively and identify ways of improving their effectiveness.

Quality controls and post-audit quality reviews aim to ensure that an SAI's audit reports and other products meet a minimum standard of quality. However, an SAI should seek to go beyond such a minimum standard. This would require the management of the SAI to be skilled, not only in the techniques of auditing, but also in the techniques of management and supervision. These skills are acquired by some managers through experience, but they also can be - and often are - learned and enhanced through effective training. The needed skills range from the ability to lead and inspire both professional and support staff on a day-to-day basis, to the more wide-ranging skills of budgeting and strategic planning. The most successful SAIs invest considerable time and resources in ensuring that managers at all levels of the organisation acquire and continuously enhance these skills.

Effective institutional management requires that the SAI have an organisational structure that maximises the effectiveness and productivity of staff resources and that it ensure excellence in the people carrying out its work.

Achieving needed changes in state entities through auditing also requires effective relations with those who have the capacity to make those changes or the influence to cause them to come about.

These matters constitute the focus of this chapter.

\section{Organisational Structure}

The way in which an organisation is structured can have a profound effect on its efficiency and effectiveness. It can also affect the quality of its work, by either impeding or facilitating individual initiative and effective direction, supervision and review. There is no single model of organisational structure or style that will meet the needs of all SAIs. Each, however, should examine its present structure and assess carefully the potential for improvements.

The structure needs to be considered in two dimensions:

- Horizontal structure refers to the number of separate units into which the staff is divided.

- Vertical structure refers to the number of layers in the management hierarchy.

The two dimensions are often interrelated. Typically, for example the greater the number of separate units, the more numerous the levels of hierarchy. However, the two dimensions should be considered separately, as they impinge on organisational effectiveness in different ways.

\section{Horizontal Structure}

Decisions about the appropriate number of operating units inevitably involve a compromise between numerous competing objectives. For example, a structure with numerous, relatively small units can facilitate specialisation and the development of expertise in particular areas of government. This can be valuable in allowing the SAI to respond quickly and effectively concerning issues in those pre-defined 


\section{GOV/SIGMA(2004)1}

areas. Typically, however, an organisation structured in that way is relatively inflexible in responding to emerging issues and changing priorities. Staff resources assigned to auditing a particular part of the state structure tend to continue working on those issues, even as the SAI's overall priorities change with time.

An organisation having fewer and relatively larger operating units, each covering a broader area of the state structure, can be more flexible in adapting to such shifts in priorities. Staff resources can be moved from one problem area to another without moving people within the organisation. This is desirable because moving people around disrupts established working relationships and can affect staff morale. However, such a structure can make it more difficult for staff to acquire the specialised expertise that can expedite auditing procedures.

Some SAIs have moved toward a "matrix" management structure, especially in the conduct of performance audits. In these arrangements, audit teams are assembled to meet the particular requirements of a specific audit. For example, a team might include auditors who are specialised in a relevant policy area (e.g. education, health, national security) along with others who have special technical or analytical skills (e.g. IT, statistics, economics). The principal auditor might be drawn from either group, depending on the focus of the audit.

Field offices, in locations remote from the SAI headquarters, are often a key element in the horizontal structure. They can be of value because of their knowledge of local conditions and their ability to respond quickly to problems within their assigned geographical area of responsibility. However, they can also severely impair an SAI's flexibility. Responding to new priorities may require people to relocate geographically, as well as from one unit to another. Some SAIs, after assessing the costs and benefits of their field office structure, have chosen to reduce the number and/or size of the field offices. Such decisions typically reflect, among other things, the vast improvements in the ease and cost of travel in recent decades, as well as the availability of high-speed, reliable telecommunications.

\section{Vertical Structure}

The vertical structure is primarily an issue for audit offices and those courts of audit having a hierarchical management structure.

Decisions about the vertical structure - the number of levels of management - reflect compromise, just as do those about horizontal structure. Some vertical management structure is obviously necessary to:

- $\quad$ provide direction, supervision, and review;

- communicate policy and procedural guidance to audit staff; and

- ensure consistency among the various elements of the organisation.

In a hierarchical organisation, there are recognisable limits to the number of individuals and operating units that a single manager can lead and supervise. These parameters, which can be found in numerous management textbooks and manuals, can be used to establish the minimum feasible number of management levels.

Most organisations, however, face a much greater risk of having too many levels of managers rather than too few. Excessive hierarchy can adversely effect an organisation in several ways:

- It absorbs staff resources, especially the most experienced auditors, who could be better employed in the actual performance of audits. 
- It can severely impede or distort the flow of communications upward and downward within the organisation.

- It can lead to excessively detailed supervision, stifling individual initiative among those at lower levels of the structure.

- It can lead to unnecessary delays in the finalisation of audit reports.

In recent years, some SAIs have made the conscious decision to "flatten" the management structure, eliminating one or more layers of hierarchy, and have thereby increased the overall efficiency and effectiveness of the organisation.

In courts of audit having a highly decentralised structure, with most management responsibility vested in constituent colleges or chambers, the problem of excessive hierarchy is less likely to arise. In these SAIs, however, the absence of strong central management makes it more difficult to ensure consistency among the various components of the SAI.

\section{Managing Human Resources}

An SAI must not only be organised for effective management, but must also have staff with the proper skills, who are trained and motivated to work efficiently at the highest quality levels. The process by which these goals are sought is commonly called "Human Resources Management". It has several components: recruitment, training, staff development, staff advancement, and the effective use of specialists.

\section{Recruitment}

Leading SAIs establish a clear strategy for recruiting and selecting new members of staff. One element of this strategy is to seek excellence in the people they hire. One technique often used is open competition for vacant positions, at both entry level and more senior levels of the organisation.

The second element of the strategy is to anticipate the SAI's future needs and recruit to fill those needs rather than simply replicating existing staff. For example, the conduct of modern attestation audits - in which the primary focus is on examining the auditee's accounting systems and internal controls - requires different skills from those involved in other regularity audits. Similarly, performance audits require a different, and broader, array of skills than financial audits. Thus the type of work the SAI expects to perform in the future should be a key part of the decision about whom to hire.

\section{Training}

Training typically comprises four components: introductory, technical and managerial training and continuing education.

Introductory training is designed to help new arrivals (at whatever level in the organisation) adapt to the unique culture and working methods of the SAI. It would address such matters as organisational structure, internal and external working relationships, ethical standards, and performance standards. Even a new staff member with long working experience will find that working in the public sector and examining public sector entities involve new and different challenges compared to working in the private sector or in academic institutions. 
Technical training is intended to equip the auditor with the methodological knowledge and skills needed to plan, execute and report whatever type of audit (financial, performance or other) he or she is expected to perform, and to do so efficiently and at a high level of quality.

Managerial training recognises that demonstrated auditing skill does not necessarily equip a person to manage or supervise an audit team. The required new skills - such as leadership, operational and strategic planning, and budgeting for time and money - become more extensive as one moves to increasingly senior positions in the organisation. Some of these skills can be acquired through on-the-job experience.

Advanced SAIs have learned, however, that such experience needs to be supplemented by formal training.

Continuing education is intended to ensure that auditors at all levels routinely undergo training in order to continuously maintain and enhance their professional capabilities. Many SAIs require all professional staff members to complete a minimum number of hours/days of continuing education each year or during another specified period.

Introductory training is typically provided within the organisation. Technical and managerial training and continuing education may be provided in-house or may be delivered through arrangements with professional organisations or academic institutions. The choice should depend on which arrangement is the most cost effective, considering the size of the SAI and the amount and nature of the required training.

\section{Staff Development}

This component of human resources management focuses on two objectives. One is to help each auditor become as proficient as possible in carrying out assigned responsibilities. The other is to help individuals prepare for more responsible positions and to help managers select the most highly qualified persons to fill those positions. Training is a vital part of the SAI's strategy in this area, but other elements are also needed.

One element of staff development is a Performance Appraisal System, through which all staff members are assessed by their superiors - against a well understood set of performance standards - for the position they currently occupy. In most advanced SAIs, performance appraisals are conducted at least annually and identify both strengths and weaknesses of the individual. In some SAIs, an auditor's performance may be assessed at the conclusion of each audit.

The information obtained from a performance appraisal can then be used to construct an Individual Development Plan, in which each person's needs for training and work experience are set out. This plan can in turn feed into the allocation of available training opportunities and the assignment of a particular individual to a position or task that will broaden or deepen that person's experience, as appropriate.

\section{Staff Advancement}

As vacancies occur in more senior positions in an SAI, it is important that they be filled by those persons who are best qualified to perform the future duties of the positions. It is equally important that the process by which this is accomplished be:

- transparent, so that everyone can understand the basis for the selection; and

- fair, so that the process can be seen to be objective, with no appearance of favouritism. 
Failure to ensure transparency and fairness in the selection process can have serious consequences on staff morale within the SAI and on the external stature of the organisation. Advanced SAIs go to considerable lengths to avoid these risks. Many use a process of open competition, in which the vacancy is widely publicised, along with the qualifications sought. Any person is free to apply for any vacant position. After an initial screening to exclude obviously unqualified candidates, each remaining candidate is interviewed by several senior managers who assess his or her background, experience and qualifications in comparison to the established requirements of the position. These assessments are then delivered to a selecting official or panel for the final decision. Typically, the selecting official would be the immediate superior of the vacant position, but the final decision - depending on the sensitivity of the position - may require approval at higher levels in the SAI.

\section{Effective Use of Specialists}

No individual possesses all of the knowledge and skills needed to perform every type of audit. Any SAI is likely to encounter situations requiring skills that are not held by the usual audit team. Some areas of specialisation, such as IT and statistical analysis, are likely to be encountered with sufficient frequency to justify hiring experts as permanent members of the staff. A common arrangement is to house these experts in one or more separate units, where they can be available to advise and assist any audit team requiring their services.

Small SAIs may judge that it is not cost-effective to employ many specialists on a full-time basis. Even a large SAI, with a wide range of specialists, will encounter situations in which no internal staff member has the precise skills needed for a particular audit. Whether large or small, the SAI should anticipate the need of bringing in the required specialists for the duration of the audit. To accomplish this, it is vital that the SAI maintain links with the potential sources of this specialised knowledge: individuals, professional organisations, associations, and academic institutions.

In addition, because of the key role such temporary employees or consultants may play in conducting an audit, the SAI should anticipate the need to "vet" them with respect to both their expertise and the absence of any conflict of interest. Furthermore, the SAI should establish procedures (such as a "peer review" of an expert's work by other experts) to ensure that the work meets the SAI's quality standards.

\section{Managing Institutional Risk}

Not all audits are equally difficult and risky. Some are relatively simple and straightforward, with relatively low probability of encountering unexpected problems. Others are much more complex, with considerable uncertainty. The latter cases present a much greater risk of "audit failure", which - especially if the audit involves matters which are highly visible and/or politically sensitive - could undermine the SAI's stature and credibility.

Many auditors respond instinctively to these differences, adjusting their plans and management attention to the relative risks of the audits in which they are involved. A better and more reliable approach, however, is for the SAI to establish a clear procedure for assessing these institutional risks and adapting itself to them.

An appropriate risk management procedure would start with a documented assessment of the risks associated with each audit, considering such matters as:

- complexity of the audit;

- audit costs;

- controversy associated with the matters being audited; 


\section{GOV/SIGMA(2004)1}

- likely cooperation or resistance by the auditee; and

- existence and effectiveness of internal audit and internal control systems.

Based on this assessment, management can make explicit decisions to allocate scarce resources - such as technical expertise and management attention (intensity of direction, supervision and review) - where they will best serve to minimise institutional risks. For example, if an audit is deemed to involve a higher than usual degree of risk, the SAI may decide to assign a more experienced principal auditor and audit team and may require more than the usual levels of review of the audit work and report.

\section{Managing External Relations}

Effective management of its human resources and institutional risks, together with effective quality control and quality assurance systems, can ensure that the SAI is capable of producing high quality, influential work. However, the overall effectiveness of the SAI in achieving greater accountability, economy, efficiency and effectiveness in government entities depends critically on the relationships it establishes and maintains with others. Highly effective SAIs typically devote considerable management time and attention to strengthening these relations. One of the most important among these, the SAI's relations with parliament, was the subject of a prior SIGMA Paper ${ }^{4}$. Other relationships, however, are also important and warrant continuing high-level attention by the leadership of the SAI:

- Mutually supportive relations with the Ministry of Finance are vital to achieving improvements in government accounting and internal controls, objectives which should be shared by both organisations.

- Mutually respectful relations with line ministries and state agencies are necessary to allow auditors to do their work efficiently, without inappropriate interference and impediments, and to encourage appropriate responses to issues identified in the audit process.

- Good relations with the media are necessary to ensure that the public is aware of the important SAI products and of the actions taken (or not taken) in response.

- Good relations with private sector auditors and relevant professional associations can lead to sharing experiences that can strengthen quality in both sectors.

- Good relations with the academic community can facilitate drawing on that source of specialised expertise, when needed, and in recruiting high quality graduates.

- Good relations with other SAIs can facilitate the exchange of experience through bilateral and multilateral meetings, exchange of auditors and/or joint audits.

Developing each of these relationships successfully requires a clear strategy in each case, and may entail considerable effort by the SAI.

\footnotetext{
${ }^{4}$ Relations between Supreme Audit Institutions and Parliamentary Committees, SIGMA Paper No. 33, CCNM/GOV/SIGMA(2002)1, 9 December 2002. Available on the SIGMA web site, www.SIGMAweb.org.
} 


\section{Conclusions}

Ensuring high levels of quality in an audit organisation involves a succession of steps that must be taken over a period of time. In fact, it is a never-ending process of continual improvement. The first requirement is to define the standards of quality and then to put quality control procedures in place that will ensure that these standards are met. These procedures need not - and should not - suppress the initiative and good judgement of the auditor in adapting to particular circumstances. However, if the auditor judges that it is necessary to depart from the usual audit techniques, it is incumbent upon the auditor to demonstrate the necessity of doing so, and to show that the approach he or she has chosen is capable of satisfying the audit objectives.

The next stage in the evolution of an SAI's quality management is assurance that quality control procedures are working effectively and identification of ways of improving the effectiveness and/or efficiency of those procedures. The best technique for accomplishing these tasks is the use of various types of post-audit quality reviews.

Achieving true excellence requires going even further. It requires building an institutional culture in which high quality is a fundamental value that is reflected in the management of the SAI and in its relations with other institutions. 


\section{ANNEX A: PRACTICES IN COURTS OF AUDIT}

This annex describes the quality control and quality assurance practices in selected courts of audit. It includes both courts in which there is a substantial degree of central management and those in which most managerial authority is vested in separate chambers of the court.

Readers should recognise that these descriptions were prepared at a particular time and that the conditions described, while accurate at the time, may well have changed.

\section{AUSTRIA $^{5}$}

\section{Quality control in the planning phase of an audit}

Every audit is defined as a project. The audit process is analogous to the project organisation. The organisation consists of the project team, which is headed by the audit manager (project manager) and the audit principal (normally the responsible director general), who commissions and steers the audit. The project team works on the individual project phases; the audit findings are submitted to the audit principal for preliminary approval.

Before the audit is commissioned, the audit team drafts an audit plan which contains agreed minimum contents (in particular a description of the audit object, the audit purpose, themes, methods, the schedule and the costs), which is submitted to the audit principal for approval. The audit manager determines the thematic responsibilities of the audit team members.

\section{Quality control in the execution phase of an audit}

During the audit phase, the audit manager conducts regular team briefings with the audit team to harmonise the findings and the assessments made (e.g. criticism, praise, recommendation). He discusses with the audit team any adjustments to the audit objectives as against the audit plan.

The audit manager informs the audit principal in due time of deviations from the audit plan, suggests modifications and seeks the approval of the audit principal.

A milestone briefing is held at least once during the on-site audit phase between the audit principal and the audit team. During this briefing, the project course is monitored by means of a comparison between the audit plan (target) and the progress of the audit (actual).

The audit manager verifies whether the audit findings and evaluation results are covered by the material surveyed (e.g. documents from the auditee, interview protocols, recordings). The audit team documents the survey results and the stages of the audit.

Using the audit findings, the audit team assesses the extent to which the auditee has accomplished its tasks and achieved its objectives. The audit manager verifies that the responsible stakeholders, together with the auditee, were given an opportunity to state their case.

\footnotetext{
${ }^{5}$ Contribution received on 14 November 2002 from the Court of Audit of Austria
} 
At the very end of the on-site audit, the audit team presents to the auditee in the form of a debate the major findings and preliminary assessments of the audit that was performed. Together with auditee representatives, the audit team looks for forward-looking solutions (element of the advisory function of the Court of Audit).

\section{Quality control in the reporting phase of an audit}

At the start of the reporting phase, the audit manager agrees with the members of the audit team on objectives, issues, content and scope of the contributions to be provided by team members to the written audit findings (i.e. the report to the auditee) and sets the rules for co-operation and flow of information.

Every auditor is obliged to document audit statements with corresponding factual material. Figures are cross-checked by a second member of the audit team for their validity and correctness (four-eye principle).

The audit manager condenses the contributions received from individual team members into uniformly structured audit findings which are free of contradictions and discusses the edited contributions with the respective team members.

The audit manager ensures that the aspect of chronology, logic and comprehensibility of the audit statements is given due importance by ranking and weighting the contributions. Moreover, he makes sure that the presentation is balanced, in both qualitative and quantitative terms. He ensures a distinct separation of facts and assessment (e.g. criticism, praise, recommendation) and verifies whether there is an assessment of every fact which expresses a clear standpoint of the Austrian Court of Audit.

Before the written project findings are finalised, the audit team presents the envisaged contents to the auditee in what is called an exit meeting. The audit team weighs the relevance and validity of the facts surveyed and of the assessments made against the statements of the auditee.

The audit findings, which have been edited by the audit manager and modified as necessary, are discussed with the audit team. A comparison between the audit plan and its implementation is made, and major deviations are justified.

The draft audit findings are then submitted for preliminary approval to the audit principal, who reviews the report as to its consistency with the audit assignment. Finally, the report is authorised by the president of the Court of Audit.

\section{Practices relating to Post-Audit Quality Assurance}

After the audit findings have been authorised, the audit team evaluates the audit process and discusses possibilities for improvement.

The Court of Audit transmits the audit findings to the auditee for comment and to the federal ministries having subject-matter competence (this practice concerns audits performed at central level; similar arrangements apply to regional and local audits).

The audit team studies the merits of the comments received and drafts a counter-comment (rebuttal) if the comments received cannot be accepted by the Court of Audit. The counter-comment is submitted to the President of the Court of Audit via the audit principal for approval. The comments and counter-comment are incorporated in the Court of Audit's annual report. The annual report is submitted to the relevant general representative bodies (at central level, to the National Council; at regional level to the province parliaments (diets) in the nine provinces; at local level to the municipal council for local communities of at 
least 20,000 inhabitants, for which the Court of Audit has audit competence). The annual report is published and made available to the general public (also on Internet - www.rechnungshof.gv.at).

The appropriate general representative body or the relevant Public Accounts Committee discusses the report of the Court of Audit and may demand further information on the report from the President of the Court of Audit. Quality assurance - in terms of follow-up of audit recommendations by the Court of Audit at parliamentary level, which goes beyond the audit process - is provided through the dissemination of the audit findings via the media and through the annual preparation - based on the reports of previous years of an updated list of recommendations which have not been acted upon.

\section{Practical problems in operating Quality Control procedures and lessons learned}

Audit processes are regularly evaluated with a view to their further improvement and acceleration.

\section{FRANCE}

\section{The French Court of Accounts:}

- $\quad$ acts as a court (since 1807);

- acts as a controller of the good use of public money;

- $\quad$ assists the parliament and the government;

- informs the parliament, the government and the citizens.

\section{General principles:}

- independence from both parliament and government;

- impartiality of its members in the decision-making process;

- $\quad$ high profile of recruitment of the magistrates;

- collegiality;

- full respect of the defence rights of auditees.

\section{Organisation:}

- The Court is presided over by a First President.

- Like all other French courts, the Court of Accounts is assisted by the Parquet général, which provides the Court with legal advice, takes part in the quality control process, and in some limited cases acts as public prosecutor. The Prosecutor General, assisted by advocates general, heads the Parquet. 
The Court is divided into seven chambers.

Each chamber is headed by a president and employs approximately 30 magistrates and auditors, aided by clerks and assistants and in some cases by experts. The senior magistrates (conseillers maittres) act as a college.

\begin{tabular}{|c|c|}
\hline $\begin{array}{c}\text { Prosecutor General - PG } \\
\text { provides legal advice on organisation, } \\
\text { programmes and reports }\end{array}$ & First President - PP \\
& $\begin{array}{c}\text { heads services, sets the programme, } \\
\text { represents Court, sends reports }\end{array}$ \\
\hline
\end{tabular}

\section{College of CRPP: PP - PG - Presidents of Chambers- \\ with a "rapporteur général" \\ acts as a college}

\section{Seven Chambers}

act as colleges

\section{Quality control}

Quality control can be performed in five different processes, directly related to both audit and jurisdictional missions:

- programming and planning;

- $\quad$ audit implementation (execution);

- decision-making process for reports;

- $\quad$ contradictory process with auditees;

- follow up.

\section{Quality control in the programming and planning system}

As an independent institution, the Court chooses freely the audits to be implemented, except for the following aspects:

- request from parliament (in growing number with the new budget legislation);

- request from the Prosecutor General (de facto management, fines); and

- appeals laid against the regional courts judgements. 


\section{GOV/SIGMA(2004)1}

It should be remembered that the Court delivers, once a year, a report to parliament on the implementation of the previous year's finance act and - since 1995 - an annual report on the social security financing act. According to new legislation, as from 2006 the Court will also have to certify the state accounts.

The Court's annual public report is delivered to the President of the Republic and to parliament. The Court can also decide to publish special reports (average of four to six special reports per year).

The Court of Accounts has the obligation to judge every public account (930) for every fiscal year. Fiscal years can be gathered in groups of four or five years. There also remains the duty to audit and judge on a regular basis the state accounts, presented by more than 100 treasurers, as well as separate accounts for state agencies and state-owned enterprises.

Besides the above constraint, the Court can select the different public policies and public bodies for its two kinds of programme (three-year and yearly).

\section{Quality Control in the programming system can therefore consist of the following checking:}

- Is the rhythm for compulsory audit and judgement of public accounts respected?

- Do the proposed audits ${ }^{6}$ deserve to be selected according to:

$>$ the amount of public money and human resources involved;

$>$ the importance of the public policy under consideration;

$>$ the present or future context (legislative or institutional changes for instance);

$>$ the raised expectations of public opinion;

$>$ the amount and type of Court of Account resources that will be required;

$>$ the schedule?

- Are there priority assignments for the proposed and selected audits according to predetermined criteria?

- Does the yearly programme fit the three-year programme?

- Does the yearly programme fit the list of public accounts that have not been judged for a long time?

After a bottom-up process within each chamber, these different questions are supposed to be answered by the presidents of chambers before they make their proposals.

These proposals are then discussed in CRPP (College of PP, assisted by the secretariat general, Prosecutor General, presidents of chambers and rapporteur général) before adoption. The Prosecutor General has a final say before adoption. The final decision is made by the PP (Premier Président).

\footnotetext{
${ }^{6}$ Proposals normally are made by the auditors and senior auditors in charge of a sector ; they are discussed within the chamber and with its president and then forwarded by the latter to the CRPP.
} 


\section{Quality control is revisited:}

- with the mid-year review of implementation of the yearly programme;

- when the next year starts, with the review of implementation of the previous programme.

\section{Quality in audit implementation}

An auditor or a team of auditors is appointed for each control.

A senior magistrate is also appointed as "contre-rapporteur" from the very beginning, at the programming stage. He is supposed to follow the audit, answer questions asked by auditors, and assist them if needed. However, he must not impose his own opinions on the implementation of the audit itself as this would jeopardize the independence of the auditors.

The quality of the audit can by checked by several means:

$>$ existence of a mission letter from the president of the chamber, indicating the objectives, content and schedule of the audit and comparison with the report;

$>$ comparison between the programme and the actual delivery of the report (content, date, time use);

$>$ description of the methods chosen by the auditors (samples, poles, geographical areas, benchmarking, proportion between in-field audit and documentary audit, proportion of use of interviews and written documents, use of reports previously made by other sources, etc.);

$>$ presentation of the auditing process to auditees;

$>$ co-operation with other auditors (from other chambers, regional courts of audit, general inspectorates of ministries);

$>$ assistance of experts (How was he chosen? What was his contract? How was he managed? How have the results of his work been integrated into the audit report?).

All of these items should be dealt with in the methodological part, which the audit report has to start with. They can be checked in the annexed documents (dossier liasse rapport - DLR ).

During the process the team of auditors must keep confidentiality.

\section{Quality in the decision-making process for reports}

The report is supposed to present clearly and distinctly the facts, the auditors' analysis and their proposals (apostilles).

Once the audit report is available, it is sent by the president of the chamber to the senior magistrate (contre-rapporteur) and to the deputy prosecutor general (avocat général, member of the Parquet général) in charge of following the activities of the chamber, before being examined by the college of senior magistrates of the chamber. 


\section{Report review by a senior auditor (contre-rapporteur)}

At the end of the audit, the "contre-rapporteur" is expected to check that all findings and analyses mentioned in the report are based on evidence contained in documents placed in a file called DLR. When the chamber examines the report, the "contre-rapporteur" is asked to give his general opinion first and then comment on every proposal of the auditors. He may give an opinion on the quality of the audit performance according to his own enquiries. He does not write his opinion down, except on extremely rare occasions.

\section{Systematic report review by the Prosecutor General}

The "avocat général" carefully reads the report before the meeting (minimum of three weeks) and then writes a preliminary opinion on the audit, which is submitted for signature to the Prosecutor General.

This preliminary opinion deals in particular with the fulfilment of audit objectives, compares the audit to the foreseen programme, checks the consistency of any analysis related with law and regulations, indicates existing jurisprudence, makes suggestions about the auditors' proposals (especially when the Prosecutor General will be involved, for example for penal affairs, CDBF (Court of Budgetary and Financial Discipline), communications with the administration). This opinion is non-binding but has to be delivered to the chamber meeting. It is read out or summarised by the president at the beginning of the meeting (the "avocat général" seldom attends the meeting), and can help him to conduct the debate and focus the deliberation on main issues.

\section{College discussion and decisions}

Every senior magistrate may ask questions during the debate and explain his own opinions. This collegial approach is decisive for the efficiency of quality control in the decision-making process for audit reports. When consensus is not reached, which is very rare, each senior magistrate and the auditors are formally invited to vote.

\section{Contradictory process with audited bodies}

The contradictory process provides a highly valuable contribution to external quality control. It offers the opportunity to check whether the findings (both facts and analysis) are exact.

\section{Draft report sent to the audited body}

Most of the time, a new version of the audit report, called the draft report, is sent to the audited body, the responsible ministries, and any person named in the report. The draft report is written by the auditors and revised by the "contre-rapporteur" and the president himself. Based on the audit report, the draft report takes into account the results of deliberations and eliminates all personal opinions of the auditors. It can be accompanied by specific questions asked during the deliberations. Although it is provisional, it commits the entire Court.

The written responses to the draft report are sent to the president of the chamber, and then to the auditors and the "contre-rapporteur". Upon request, they can also be sent to the "avocat général".

\section{Final report}

The auditors prepare a second report (often a very short document), which summarizes the findings of the draft report, presents the responses to the draft report and the auditors' comments, and finally proposes to 
either accept the responses and correct the report accordingly or, on the other hand, to maintain the Court's point of view. In the more important cases, this second report is submitted to the "avocat général", who then drafts a second preliminary opinion, indicating that the responses have been taken into consideration and informing about the final decisions to be taken by the Court. The "contre-rapporteur" plays the same role, and the chamber holds a new meeting.

\section{Final college discussion and decisions}

The final meeting of the college can be preceded by an interview of representatives of the audited body and of the involved ministries, either at their request or at the initiative of the Court. These interviews are not transcribed.

In some cases (de facto management and fines), the meetings of the college are public. Auditees, assisted by barristers, are given the floor.

The final deliberation leads to decisions that will be embodied in judgements, transmission of cases to other jurisdictions, administrative letters to audited bodies and involved ministries, and, if necessary, publication of the final version of the responses of representatives of audited bodies. In the event of publication, these representatives are previously granted an interview.

All of these decisions call for new responses from the audited bodies, which provide a second occasion to verify the quality of the Court's findings and assertions. This new quality control will be referred to and utilised some years later through the next audit in the same body or field, but also in every mid-year report, in which the chambers examine the follow-up to their decisions.

Finally, it should be pointed out that quality control is also applied to the judgements issued by the Court. The Council of State (Conseil d'Etat) has the possibility of cancelling a Court decision when either the procedures have not been respected or the law analysis on which the decision is based is incorrect.

\section{GERMANY ${ }^{7}$}

\section{Internal and external studies on the efficiency of Supreme Audit Institutions}

SAIs are quite right to focus on the efficiency of their work. In examining the cost-effectiveness of their own work, they must apply at least the same standards as they apply in their audits of the executive branch. Firstly, adopting this attitude is dictated by the rules of fairness; secondly, it is a requirement derived from the efficiency principle; and thirdly, it is an issue of credibility. Transparency and openness in its own affairs give SAIs the degree of authority vis-à-vis parliament and its committees that they need to argue confidently and rigourously in support of their audit findings.

However, procedures for enhancing efficiency and providing assurance about quality must not distract attention from the essential issues. Given the wide variety of matters to be audited, audit quality depends -

\footnotetext{
${ }^{7}$ Contribution received on 19 November 2002 from the Federal Court of Audit of Germany (Bundesrechnungshof).
} 


\section{GOV/SIGMA(2004)1}

last but not least - on the flexibility and creativity of the auditors. This is why any quality management scheme that relies on a standardised approach does not deserve its name.

The Federal Court of Audit (Bundesrechnungshof) faces a continued challenge of seeking to achieve best practice by means of continuous updating and adaptation of its key quality management tools, i.e. its Rules of Procedure, Audit Rules and Schedule of Responsibilities. Further essential principles for ensuring high quality standards in auditing are laid down in the Court's Audit Guide. The areas to be emphasized are:

- $\quad$ analysis of tasks;

- methodological selection and prioritisation of audit assignments;

- methodological choice of audit approach from among different options;

- $\quad$ audit design; and

- evaluation of the audit procedure, audit findings and actions taken in response to the Federal Court of Audit's audit recommendations.

The details of the above tasks will be discussed below.

Furthermore, quality management procedures are in place for specific tasks, e.g. the editing of the Federal Court of Audit's annual report by Audit Unit I 1, which is responsible for fundamental auditing issues. To support audit planning, a fundamentally revised version of the Court's Automated Audit Planning and Information System (APIS) has been set up.

The Federal Court of Audit (Bundesrechnungshof) has adopted the objective of enhancing the visibility of the processes of increasing efficiency and ensuring the high quality of its audit work. However, the Court does not consider that the standardised cost and performance accounting systems used by public and private sector entities are adequate for fairly presenting the working methods and the products of government auditing. It is therefore imperative to develop solutions that meet the specific requirements of government auditing functions. The Court is implementing an experimental project, covering all of its audit divisions, which constitutes the first steps towards developing a suitable cost-effectiveness concept. Since the beginning of 2002, a system has been in place for recording the input of time and costs incurred by each senior audit director, audit director, and auditor. This system provides an overview of the use of resources.

Since October 1998 further steps have been taken to devise transparent procedures and, to the extent possible, uniform standards for all areas of audit work. A working group conducted a survey, in close conjunction with the Federal Court of Audit's "colleges" (responsible for steering the work of audit units), to identify the support needed in the form of tools for analysis and steering. Following completion of this survey, the working group set out proposals for addressing the core functions of a quality management system. These proposals have become indispensable tools for the daily work of the Court's audit units in carrying out the core functions of task analysis, audit design, and evaluation. 


\section{Analysis of tasks}

The analysis of tasks is a major key to quality management. It is the bottom line for all further steps. Task analysis is a preparatory stage for audit planning. Furthermore, it is the basis for the systematic planning of individual audit assignments. A complex analysis of tasks helps to better identify gaps in audit coverage. Finally, task analysis enables the Federal Court of Audit (Bundesrechnungshof) to target its limited audit resources so as to achieve optimum audit impact.

Where the remit of an audit reflects the remit of one or several government departments, task analysis can start by analysing the sub-headings of the departmental budget(s) concerned. Such an analysis may generate information which is useful for defining areas to be audited and identifying the appropriate methodological audit approach.

In order to work out a meaningful overall analysis of tasks, it is necessary to have set out the criteria that enable the formulation of a systematic description of tasks that is at least comparable for a group of audit units. The classification of descriptions of tasks into types may take into account the budget structure within the departmental budget, the volume of expenditure, audit subjects, audit focus, and audit criteria.

\section{Audit design}

Given the usually vast amount of matters to be audited that have been identified by the analysis of tasks, it is then necessary to define individual audit subjects that are capable of being selected for audit planning. It is therefore necessary to determine descriptive criteria for the selection of audit subjects. These criteria must embody the clearest possible interpretation and specification of the pertinent provisions of the Federal Court of Audit's Audit Rules (section 13, para. 1, sentence 2; section 13, para. 2; and section 15).

As a next step, the question to be asked is how a given audit subject can be segmented and arranged by themes by means of choosing suitable audit criteria, audit types and audit approaches. The point of departure for the formulation of such criteria is again to be found in the Audit Rules (audit topic: section 17, para 1 of the Court's Audit Rules; audit criteria: section 4 of the Audit Rules; types of audit: section 18 of the Audit Rules). If, for example, a government department or agency has not yet been audited or has not been audited for a long time, a general audit will be most suitable for obtaining a comprehensive overview of its financial management and operations. If a general audit of the entity in question has been carried out fairly recently, a follow-up audit is suggested, perhaps supplemented by a selective audit of a small sector of operations in the event that the previous audit had generated findings suggesting a need for, or the expediency of, an in-depth examination. Where the granting of statutory benefits is concerned, various audit approaches are conceivable. Apart from verifying the accurate granting of benefits, it may be appropriate to audit their funding or the impact which the pertinent statutory provisions have in terms of equitable results and input of administrative resources. In the latter case, however, no straightforward criticism may be expressed, and only recommendations may be given. Audits of projects, programmes and systems may give rise to questions about the need, the potential overlap with other measures, and the consideration of possible alternatives.

Where audits have been adequately defined in terms of subject, approach, type, and audit criteria, suitable criteria must also be found for prioritising audit assignments in a meaningful way, while keeping in mind the limitation of audit resources. In this regard, audit planning would be supported pursuant to section 14, para 3 of the Federal Court of Audit's Audit Rules.

To prepare individual audits, those in charge must be able to draw from a number of characteristics which make it possible to determine audit objectives, audit focus, time schedule for the audit, audit scope, and methods to be used. All of these factors enable the steering and evaluation of the audit (audit design, 
embodied in an audit schedule: section 23 of the Court's Audit Rules). The audit design is preceded by the collection of material, i.e. the gathering and analysis of documents and information on the audit topic. Accessible sources should be drawn on in a comprehensive fashion. The analysis of the material gathered at this stage may also influence the audit subject and audit focus. The audit schedule sets out the reason or motive underlying the audit, the audit topic and the audit objective. It specifies the audited bodies and, where necessary, any other bodies on whose premises audit evidence is to be collected. Furthermore, it identifies the auditors to be assigned to an audit exercise and indicates the time schedule for the successive steps according to which the audit will be carried out. The audit schedule must explain the approach to be adopted, the volume of matters to be audited, and the audit methods. All of the components of the audit schedule taken together form a structure of objectives and targets which must be compared to the actual accomplishments during all stages of audit implementation.

\section{Evaluation of audits}

Evaluation is not a single action but rather a process that accompanies each audit exercise. The evaluation process serves to improve the audits already underway and to generate knowledge for future audit assignments. At the core of the evaluation is the comparison between the structure of objectives and targets and the actual accomplishments at each stage of the audit. This comparison generates conclusions, especially with regard to optimal steering of the current audit exercise, improvement of future audit planning, and selection and presentation of audit results to the addressee(s) of the audit report.

It is appropriate to evaluate an audit exercise after completion of the collection of audit evidence in situ and at the time of drafting the audit record. Audit results should be evaluated after receipt of the comments of the recipient of the management letter and on completion of the audit. The results of the evaluation are recorded in writing.

\section{Approach and results}

The Federal Court of Audit's working group on quality management has provided the "colleges" and auditors involved with guidance and checklists that enable them to carry out the analysis of tasks and the evaluation on their own. The adaptation and further improvement of these tools have been the subject of a continuous exchange of ideas between the working group and audit divisions. Major findings and guidance on procedures have been included in the Court's Audit Rules and Audit Guide. The Court will continue the process of further refining its tools so as to generate findings and steer its audit work. The Court's continuous efforts in this area are motivated by its conviction that government auditing cannot rely, without close consideration, on "cut and dried" solutions that may be suitable for other public or private organisations. The Court therefore remains committed to developing specific tools for monitoring mission performance and ensuring the high quality of its work, keeping in mind the specific challenge of government auditing. The Court primarily considers this continuous perfection effort as its own task, which must be performed concurrently with the performance of its audit functions, and it therefore makes high demands on internal communication and steering. Setting high standards for audit work and continuously monitoring compliance with these standards represent a basic task of government audit bodies. Given the nature of their mission, they can hardly draw on external support except in isolated cases, and any such support will necessarily be limited in terms of impact. 


\section{ANNEX B - PRACTICES IN AUDIT OFFICES}

This annex describes the quality control and quality assurance practices in selected audit offices. These offices all have a hierarchical management structure, typically headed by a single official, who often has the title of Auditor General. Sweden is an exception in this regard, having three Auditors General of equal stature.

As in the previous annex, the reader should recognise that this material reflects conditions as they existed at a particular time, and that those conditions may have changed.

\section{DENMARK ${ }^{8}$}

\section{Introductory remarks}

In 2002 the National Audit Office of Denmark (NAOD) started the work of implementing a new audit support system, referred to as TeamMate. The system, expected to be operational as from 1 January 2003, will result in significant changes in quality assurance procedures and quality control.

The following contribution describes NAOD's experiences with quality assurance in financial audit as well as performance audit.

NAOD deliberately chose the term "quality assurance" rather than the expression "quality control". Assurance has positive connotations, as opposed to control, which gives the impression of negative sanctions. The philosophy of quality assurance is not to point fingers at anyone, but to learn and develop audit services delivered by NAOD based on its professional qualities.

In a modern audit organisation, quality assurance - as reflection - is becoming a theme of its own - a learning process, which creates a feedback loop for initiating an improvement process. It is a consequence of the fact that the audit process produces audit evidence as documentation for the auditor's reports and statements, and concurrently any audit implies a certain audit risk. In a modern SAI, quality assurance is a means to reduce the audit risk in the audit process. Quality assurance establishes a learning process, and the final aim is to improve the audit process and reduce the audit risk fundamentally.

According to the National Auditing Standards established for public sector audit in Denmark, it is essential that the quality of the audit is evaluated during the audit process. The aim of this evaluation is to provide assurance of the quality of the audit being carried out.

It is stipulated in the National Auditing Standards that a precondition for quality assurance is the existence of agreed audit objectives and procedures, which have the purpose of assuring an acceptable level of quality of audit tasks. It is essential that audit plans are prepared and that staff members have the required qualifications to carry out the audit task.

\footnotetext{
${ }^{8}$ Contribution received on 15 November 2002 from the National Audit Office of Denmark
} 
The purpose of quality assurance is to evaluate to what extent stipulated policies and procedures are followed, and to establish whether they have had the intended impact on the audit.

\section{Planning}

On the basis of the National Auditing Standards, NAOD developed an audit manual describing procedures and audit products. These descriptions include the requirements for planning the audit product, implementation of the audit product, and the essential documentation in each audit file.

The audit manual provides the baseline for evaluating the quality of audit work. The manual is the starting point for answering the following questions:

$>$ To what extent do auditors follow the audit planning and implementing procedures established in the audit manual?

$>$ Does the audit file contain the relevant planning documents and audit documentation, which gives NAOD sufficient audit evidence?

The planning of the audit is divided into two phases. By way of introduction, an overall planning and ordering of priorities takes place, after which individual offices plan and prioritise the various audits.

\section{Overall planning}

When planning the audit, an attempt is made to ensure coverage of the state accounts, as this coverage provides the basis for the Auditor General's report on the state accounts, in which an opinion is given on the quality of the state accounts and on the accounts of individual areas of a ministry. Plans are outlined so that the individual products may together ensure satisfactory coverage of the state accounts.

The annual plan for NAOD's financial audit has to be prepared on the basis of the overall strategy and performance targets announced each year by NAOD management.

In the planning process, individually planned audits are registered in a database. Furthermore, the ongoing updating of the database is carried out concurrently with the execution of the audits.

\section{Quality control on the administrative level}

In accordance with the rules, it is the director's responsibility to ensure that the quality of the planning corresponds to the internal audit guidelines. It is also the director's responsibility to ensure that the audit is carried out as planned. In practice, the auditors assure the quality of each other's work, and the director subsequently endorses and approves the planning of the audit.

\section{Performance}

NAOD refers to the responses given under the heading "quality control on the administrative level", as the procedures for quality control when carrying out the audit are the same.

The quality assurance of performance audit is different from that of financial audit because the circumstances and conduct of performance audit are dissimilar from those of financial audit. 
After several years' experience with internal quality assurance of special audit reports, NAOD considered that the evaluation process had deteriorated. There was a need for a new quality-assurance process that could give more input to the internal development and learning process.

For that purpose, a panel was established of six independent university professors from different Danish institutions and from disciplines such as law, economic, accounting and political science. NAOD invited these evaluators to present their professional assessment of performance audit $\left(\mathrm{VFM}^{9}\right)$ reports, with the aim of identifying possibilities for improvement. The results of their examination were presented in a written report. The evaluators later reported orally to the group of auditors who had prepared the NAOD reports. The external evaluation of VFM reports is an ongoing process.

The evaluation reports are accessible to all members of staff on NAOD's intranet. Upon request, the evaluation reports can be handed over to the press or to any citizen demanding these documents under the Freedom of Information Act.

The external evaluation report includes both the content of the performance audit report, the methodology and questions as well as the presentation of observations and findings.

The results of the first evaluations were generally positive. All of the evaluated performance audit reports were of a high quality, and the presentation of the subject gave the impression that the area had been carefully examined. Data had been collected properly, and the analysis had been carried out in a professional way, even though the methodology was not always sufficiently sophisticated.

\section{Reporting}

NAOD refers to the responses given under headings "planning" (1) and "performance" (2), as the procedures for quality control when carrying out the audit are the same.

\section{Problems with quality control}

NAOD has not yet experienced any particular problems, as it will not start using TeamMate exclusively before January 2003.

\section{Closing}

In November 2000 a working group was set up with an Assistant Auditor General as chairperson. Two directors and several senior auditors were appointed as members of the working group.

The group started with a seminar to discuss the approach to quality assurance. To obtain more information on the subject, colleagues from a local commercial auditing firm were contacted, and its leading partners were interviewed with respect to their experiences with quality assurance. These colleagues had recently carried out quality assurance within their own audit firm. This information-sharing provided some ideas on how to avoid in particular some social-psychological problems when controlling audit files produced by other colleagues.

The group developed the necessary working documents, such as concept papers, guidelines for quality assurance, and questionnaires.

\footnotetext{
${ }^{9} \mathrm{VFM}=$ Value for Money
} 


\section{GOV/SIGMA(2004)1}

The selection of audit files was made in collaboration with the responsible director and auditor. The quality assurance group chose to analyse average audit files, rather than the poorest or most perfect files, as they would be representative for the process. This selection was not a theoretical attempt to establish a representative sample of audit files, but it worked in the social setting in which it was applied. It was especially important that everyone accept the findings based on the audit files that had been scrutinised.

On the basis of the examination of selected audit files, the general conclusion was that NAOD had conducted an audit of good quality. Of course, there was still room for improvement in different phases of the audit process and in terms of audit documentation.

\section{FINLAND ${ }^{10}$}

\section{Financial Audit}

\section{Quality control in the planning phase of an audit}

- The financial audit manual requires preparation of an audit plan based on risk analysis, which in turn requires sufficient familiarisation with the client, its accounting system, and the management style of its head. Familiarisation with the client encompasses (a) provision of regulations and other norms, descriptions, plans, budget, performance contracts, reports on activities and audit reports; (b) discussions with the audit manager and with the previous auditor if the client's auditor has changed; (c) knowledge of performance audits of the SAO and other auditors in the client's sphere of operations; (d) knowledge of client's financial rules; and (e) establishment of preliminary analytical procedures.

- A written risk analysis document and audit plan are required. The audit manual determines the contents of the audit plan in general terms and provides an audit plan example. The audit manager reviews the risk analysis and audit plan documents and guides auditors in the improvement of these documents. The audit manager signs the audit plan when he/she is satisfied that it is in line with the manual and with any requirements set by the head of the department.

- $\quad$ The audit plan must be completed by a fixed deadline.

\section{Quality control in the execution phase of an audit}

- Audit procedures are documented in the audit manual and its annexes. Audit managers control the execution of audits based on their judgement. It is up to each audit manager to decide what comprises this control. However, if problems cannot be resolved in co-operation with the accountable auditor and her/his audit manager, the latter turns to the head of department.

- The audit manual requires auditors to submit at least two intermediate reports during the audit.

- The auditors report the number of days they have worked on various audit projects and other activities; these reports are also sent to audit managers.

\footnotetext{
${ }^{10}$ Contribution received on 11 November 2002 from the State Audit Office of Finland
} 


\section{Quality control in the reporting phase of an audit}

- Auditors submit intermediate reports, which describe the scope, the work accomplished, and audit conclusions and their grounds, and possible recommendations. An audit trail from conclusions to findings is required and controlled by the audit manager.

- While preparing the final audit report, auditors are required to complete a questionnaire on the audit and its results. The questionnaire can be seen as a checklist ensuring that the audit has been performed correctly in all of its essential aspects.

- A paper specifying the expressions to be used in audit reports is prepared by the head of the financial audit department; he/she also prepares a sample audit report.

- Auditors prepare a draft audit report, which is examined by audit managers. Audit managers submit the draft to the head of the department after the agreed corrections have been made.

- The reporting threshold is determined by the head of the department, who usually consults with audit managers in this regard.

\section{Practical problems in operating the Quality Control procedures and lessons learned}

Some problems have arisen with regard to the reporting threshold.

\section{SWEDEN ${ }^{11}$}

\section{Quality Assurance in the Swedish National Audit Office (RRV)}

This paper summarises RRV's approach to quality management and quality assurance. It is more of a Total Quality Management (TQM) approach, providing standards, advice and follow-up on all major activities within the RRV that affect final quality.

RRV works with the full scope of audits (performance audit and financial audit) and with a broad audit remit covering the whole state sector, including state-owned or state-controlled enterprises, state foundations, and governmental grants to municipalities and counties. In July 2003 RRV was transferred from the executive branch to the legislative branch (parliament).

RRV regards its commitment to Quality Management (QM) as an ongoing activity, reflecting the continuously growing demands and expectations of the public with regard to the audit profession. The ambition for financial audit is to match the professional standards of the private sector in all relevant aspects, and for performance audit the ambition is to apply a reasonable number of academic criteria to research reports. The present $\mathrm{QM}$ status represents a successive improvement, over a periiod of several years, along a development curve. In recent years more focus has been placed on a Total Quality Management (TQM) approach, and the investments in QM have been more costly. In the earlier phases of the development of QM, the RRV tried to avoid professional mistakes in assessing irregularities, bad

11 Contribution prepared by Bo Sandberg (National Audit Office of Sweden), SIGMA expert (received on 18 November 2002, with minor revisions on 15 February 2003) 


\section{GOV/SIGMA(2004)1}

management, and low efficiency and effectiveness with regard to our clients. This was a major concern at all levels of "supervision", i.e. quality checks of draft reports before finalising audit work. As a result, for financial audit the RRV refocused on the more demanding task of presenting a well grounded professional assessment of annual financial statements, in line with the Generally Accepted Auditing Standards (GAAS) of the INTOSAI and IFAC type. In performance audit the RRV refocused on the study of better defined "audit questions" on the increased use of Generally Accepted Academic Criteria (GAAC) for collecting and analysing information.

More important common TQM platforms created and supported by broad staff commitment and participation are:

- $\quad$ a mission and vision statement;

- a code of ethics;

- an annual performance assessment of staff.

\section{Financial Audit}

A Total Quality Management (TQM) concept has been thoroughly analysed, debated, accepted and documented in an "Audit Guide" (RRV 2000:22, available in English). In this combined policy paper and main standards the major cornerstones are defined. The quality work is categorised as the ambition to build in quality in all stages of audit: a) input quality, b) process quality, and c) results quality.

\section{Input quality}

A certification programme for financial auditors over a period of five years, with 400 hours of lectures, designed to start from an academic degree in accounting. An external examination is performed by the association that certifies chartered accountants in the private sector. One examination is set up after three years and the final examination after five years. The examinations are the same (to a 75\% degree) as for auditors in the private sector and are given on the same day. To date $90 \%$ of the staff have started this programme. A financial salary incentive of $+10 \%$ after being "certified" is applied.

A well defined hierarchy of audit responsibilities has been established that is similar to the hierarchy applied in the private sector: 1) auditor in charge 2) assignment leader 3) examination leader and 4) participating auditor. To be promoted to the highest levels requires, among other qualifications, the certification described above.

\section{Process quality}

Each year the RRV carries out internal (crosswise between auditors in charge) quality follow-up of onefifth of its assignments. This follow-up is clearly of a quality assurance (QA) type. To date, after five years of implementation, all (i.e. several hundred) audit assignments have been followed up and documented at least once.

RRV has a contract with a chartered accountant firm that verifies annually how this internal crosswise follow-up is working and reports back to the Assistant Auditor General. 


\section{Results quality}

Routines have been established for a systematic follow-up of RRV work. Audits are evaluated from different perspectives, such as: a) efficiency of work, b) comments and observations made during the audit, and c) actions taken on audit findings and recommendations.

Questionnaires completed by ministries and agencies provide the RRV with the recipient's opinion of the quality of RRV work with respect to scope, focus, access to the auditor, expertise, and relevance in the areas examined. The surveys are carried out every third year; the last surveys, carried out 2001 and 1998, both resulted in good appreciation in almost every aspect. This fact has proved to be very valuable in discussions with the RRV principal.

\section{Common quality issues for financial audit}

An Advisory Audit Committee and an Advisory Accounting Committee have been set up, with senior staff members providing professional advice and guidance on audit and accounting respectively.

A well defined and stratified Reporting Strategy targeting the different decision levels of principals and auditees has resulted in issuing: a) a Formal Audit Opinion, in line with INTOSAI Auditing Standards and IFAC Guidelines, to the government; if qualified, a copy is sent to a standing committee in parliament; b) an Audit Report, with more detailed findings and recommendations where applicable, to the board of the agency; and c) an Audit Memo to the Chief Finance Officer of the agency, if applicable. Once a year RRV forwards a consolidated Annual Audit Report to the government, with copies for information sent to the standing committees in parliament. This report sums up major findings and recommendations on both financial audit and performance audit.

A chartered accountancy firm has been contracted to prepare a policy paper that follows up how the TQM audit concept works [General Controls of the application of Generally Accepted Auditing Standards (GAAS) and Rules of Professional Ethics for Accountants (RPEA)]. The most important aspects of the general controls are: a) the auditor's independence from the client; b) sufficient staffing, with adequate qualifications for the audit assignment; c) necessary guidance for the audit team; d) existence of an inspection programme on the QC/QA for GAAS and RPEA. The chartered accountancy firm reports to the Assistant Auditor General. This arrangement is thus of an external peer review type.

\section{Performance Audit}

The Total Quality Management (TQM) approach for performance audit has been designed with due respect to the special character of the RRV focus on effectiveness. More and more interest and resources have been devoted to build in quality in the first place. Here a suitable structure comprises the three audit phases: planning, execution, and reporting.

\section{Planning}

To improve the quality of audit planning, RRV performs more substantial studies, each referred to as "Area Strategy for XX". The purpose of such studies, normally 30-70 pages in length, is to highlight important auditable problems and issues in the area concerned, using the normal audit criteria: materiality and risks. A few suitable audit projects are then defined, those where the expected value-added - through a performance audit - seems to be the highest. These studies also have another function, which is to legitimise RRV as a knowledgeable actor from whom interested parties could expect to benefit from high quality contributions. 
When planning an individual audit, it is compulsory to carry out a pre-study to define the audit questions to be studied, describing and justifying the methods to be used for data and information collection and analysis, and indicating the possible benefits and risks of the audit. The outcome of this phase - a pre-study report - forms the basis and rationale for the main study, the individual audit.

In all of the planning phases to date, RRV has attempted to engage, normally as team members, high profile experts in the area concerned who have an indisputable expert prestige among the interested parties of a particular study. A relatively new feature has been to engage statistical and other research experts on a more permanent basis to provide an independent second opinion on draft reports before final decisions are made.

The outcomes of the three phases - an area strategy, a pre-study report, and a plan for the main study - are approved by the Assistant Auditor General or the Auditor General.

\section{Execution}

The team leader and team members, including external experts, run the project, with formal briefings given to the head of unit and the Assistant Auditor General. A quite frequent problem in the past was due to the fact that the project had expanded in directions not foreseen in the audit plan. Today the project leader needs to have a more formal approval to be able to shorten or lengthen the audit plan. Detailed requirements have also been set out concerning the relationship with the client during audit work.

\section{Reporting}

A quality pillar for performance audit is to have a clear distinction between facts and observations and to hold them apart from the assessment and from the final distinctive part, the recommendations. A general ambition for RRV is that the auditee and auditors should be able to agree on facts and observations. It is good if the auditee can agree on the assessment as well, not to mention accepting the recommendations. It is possible however, that an auditee will not agree on the assessment, and if adequately justified, this disagreement should be indicated.

In the reporting phase, a contradictory procedure is applied. Here the auditee is asked for comments on all facts, the assessment and recommendations made by RRV. This contradictory procedure, together with the fact that a performance audit report must include all facts and analyses made to support the assessment and recommendations, constitute the two most effective factors encouraging and fostering good quality. A performance audit report can be challenged from a quality point of view after several years, and if proven to be justified, such a claim can have serious consequences for all parties involved. Everyone is aware of this fact, which also prevents "bargaining" on the findings of a report in order to obtain the positive approval of the client.

Relevant objections and criticism made by the client should be handled within the report. An option that has been disregarded by RRV is to offer the auditee the possibility of having its own appendix to contradict RRV. The reason for not using this option is that RRV thinks that it would create uncertainty among the recipients of the report. In most cases, considerable expertise and time are needed to assess the two different opinions, which would be a detriment to the propensity to take action on audit reports. However, the auditee is asked for a formal answer within six months concerning its actions on the audit report. Of course they are also entitled to present to the media any criticism. This does happens but not often. The possibility of approaching the RRV principal, the Minister of Finance, with criticism is very seldom used. This is probably due to the fact that he/she could not interfere in any way even if the criticism were motivated. If negative comments made by the auditee appear in the media, the RRV policy is to not enter into a debate in the media concerning an audit report. This position is motivated by the simple fact that it 
could create confusion as to where RRV actually stands after delivering the report. Interviews with RRV representatives on audit reports in newspapers or on radio/television are nevertheless frequent.

The reporting of a performance audit is most crucial for RRV. Senior auditors are therefore trained by media experts to write precise and concise reports. The entire media function, for which RRV has its own experts, is crucial for the effective reception of an audit report. Getting the message through and encouraging actions to be taken on performance audit reports require good media coverage.

A special model has been elaborated for internal follow-up on performance audit reports (findings and recommendations), based on a comparison between the current year and the three preceding years, as part of the RRV dialogue with interested parties. Among the more important topics included in this model are a) relevance b) coverage of state commitments c) acceptance of audit recommendations and d) professional development.

\section{Common quality issues for performance audit}

There is a combined policy paper and guideline for performance audit that set the platform for Quality Management $(\mathrm{QM})$. The guideline provides guidance on, inter alia, the same quality aspects as for financial audit (input quality, process quality, and results quality), but with some additional aspects.

Another feature greatly appreciated by auditors is a database entitled "Audit Methods Memory". Every project, after closing its external reporting, must prepare an audit method report, describing the methods used and their application. A special audit quality group scrutinizes the draft audit method report. After approval by the group, the report is then added to the common experience database and its different aspects can be searched electronically.

\section{UNITED KINGDOM}

\section{Quality Controls in the Financial Audit Process ${ }^{12}$}

Quality control procedures within the UK National Audit Office (NAO) are governed by the UK's Auditing Practices Board's Statement of Auditing Standards (SAS) 240, which provides extensive guidance governing individual audits, and whole-of-office procedures to ensure the quality of the NAO's financial audit work.

\section{A. "Real Time" Quality Control Practices and Procedures}

Before the start of each audit, assignment directors are required to review the audit resources they have available to undertake an assignment and to confirm that the audit team is independent and suitable for the task. In addition, on an annual basis all financial audit staff are required to complete an annual code of conduct declaration, as well as a learning and development record. These documents confirm that they are

\footnotetext{
12 This section of the UK contribution was prepared by Mark Babington (UK National Audit Office), SIGMA expert (received on 22 October 2002).
} 


\section{GOV/SIGMA(2004)1}

"fit and proper" people (in accordance with UK Audit Regulations) to conduct an audit, and that they have kept their professional knowledge up-to-date.

The review is carried out in two stages - a first-stage, detailed review by an assignment manager or team leader, and a second-stage review of major judgements, conclusions and evaluations by an assignment director. For those assignments deemed to be of high value, high risk, or subject to qualification, a second, independent director also reviews major decisions and judgements at each stage of the audit, from planning to conclusion.

The NAO provides a central technical support service to give advice and guidance to audit teams where needed, in accordance with office policies on consultation. Where a qualification of an audit opinion is proposed, the central technical team provides an additional layer of review before the opinion is submitted to the Comptroller and Auditor General for certification. Guidance can also be sought within each line unit from the lead Financial Audit Director.

\section{B. Post-Audit Quality Review}

The UK NAO carries out a "cold review" round annually. This round provides assurance to senior management of the quality of the NAO's financial audit work. A sample of about $5 \%$ by number and 8$10 \%$ by value of audits is reviewed. Each assignment director is covered once on an annual basis, and each manager is covered once every three years. In accordance with SAS 240, separate members of the management board are responsible for audit quality and for technical audit methodology.

An experienced manager and director team carries out reviews. At the end of each review, audits are graded. If there are any audits that are deemed to be weak, the account will be reviewed again during the following year. In the same way, an example of the work of any manager or director previously associated with a weak audit will also be reviewed during the following year (once for a manager, twice for a director).

An annual report is prepared for the NAO management board, and the findings of the NAO's cold review round are also disseminated throughout the office so that weaknesses can be addressed during future planning rounds.

The NAO is also subject to review by the Joint Monitoring Unit, the quality standards monitoring body of the Chartered Accountancy Institutes. Its monitoring procedures incorporate a series of cold reviews and an examination of NAO office procedures designed to ensure the quality of NAO staff. The Unit produces a report for NAO management, the findings of which are disseminated to staff to ensure that the relevant issues are addressed during future audit rounds.

\section{Good Practices}

- Regular and timely dissemination of results of review rounds to the whole office to ensure that any problems are addressed promptly;

- Independent assessment of the quality of NAO audit work;

- Cold review process encouraging reviewers to identify areas of good practice, which can be shared with colleagues in future;

- Independent director review and central technical support team providing validation of key judgements and conclusions. 


\section{Quality Controls in the VFM Audit Process ${ }^{13}$}

\section{A. "Real Time" Quality Control Practices and Procedures}

The objectives of NAO quality assurance are to:

Organise the NAO's VFM work so that quality assurance is an integral part of it at all stages;

$>$ Evaluate the strengths and weaknesses of VFM outputs and their management in order to learn and apply the lessons for future work;

$>$ Provide senior management with systematic and reliable information about the quality of VFM examinations.

Project directors and their teams are responsible for delivering their approved programmes of VFM work to high quality standards. They must determine the most appropriate form of quality assurance, depending on the size and complexity of the examination, its sensitivity, its duration and the experience of staff undertaking the work.

\section{Obtaining expert advice and second opinions}

Actions and procedures to provide quality assurance include:

$>$ Consulting expert opinion, either internally or externally, to advise on key aspects of VFM examinations at critical stages, especially at the design stage, before crucial decisions are made;

$>$ Sources of expert opinion include, internally, the Technical Advisory Group and externally, specialist consultants and panels of academics and other experts;

$>$ "Hot edits" - independent reviews of reports while they are being written to assess whether they are technically sound, the structure is convincing, evidence is clearly presented, and that generally the report is likely to convey its messages simply and quickly to the reader;

$>$ Requirement that work must be reviewed by experienced staff not directly involved in the work.

\section{Building-in quality}

Good management and review can also promote quality, and assurance can be assumed when there is evidence that this good management and review are reliable and consistent. This assurance is provided in the following ways:

Assigning staff with the right skills and experience to appropriate study tasks;

$>$ Frequent communication with staff so that they all understand their roles and tasks within the aims and context of the examinations;

\footnotetext{
${ }^{13}$ This section of the UK contribution was prepared by Mark Popplewell (UK National Audit Office), SIGMA expert (received on 29 November 2002).
} 
$>$ Regular discussions with staff to determine what worked well, what was less successful and the reasons, the scope for improvement, and how it might be implemented;

$>$ Documenting key evidence and its interpretation so that there is a good trail to demonstrate how decisions influencing the examination and its conclusions were reached;

$>$ Monitoring study progress and costs to anticipate problems and to intervene early enough with appropriate action and solutions;

$>$ Comprehensive and timely review of work to ensure that all conclusions are soundly based and supported by reliable and sufficient evidence.

\section{B. Practices relating to Post-Audit Quality Assurance in the Audit Process ("Cold Reviews")}

There are four types of post-study completion reviews: internal evaluations, external evaluations, feedback from the audited body, and team review. No single assessment is key, and the aim of the assessments is to enable the NAO to continue to improve its work by learning lessons.

\section{Internal reviews}

The team that carried out the study reviews published reports using a standard format. Assessments cover:

$>$ presentation and format;

$>$ technical content and quality;

$>$ initial impacts;

$>$ general assessment.

\section{External reviews}

To obtain an independent perspective on the quality of NAO work, the Office appoints an external organisation to review NAO's published reports. The external reviewer is usually an academic body recognised as a centre of expertise. The reviewer draws on a panel of academic experts from a range of disciplines. The experts receive copies of all reports as soon as they are published. The panel assesses the reports against similar criteria used for internal reviews. The external reviewers normally produce two summary reports each year, bringing together the key messages conveyed in their quality assurance reviews.

\section{Feedback from audited bodies}

The views of audited bodies that are subject to NAO's VFM examinations are important, including their perspective on the impact and added-value obtained by the study and their opinion as to whether the study was well managed and the staff acted professionally. Feedback from audited bodies is requested in a standard format and sent to the audited body by the study director after the report has been published.

\section{Team review}

Teams carry out a "lessons learned" review once the report is published, to determine:

$>$ what worked well and why;

$>$ what was less successful and the reasons; 
$>$ lessons for the future and possible wider application for all VFM examinations.

\section{Acting on findings}

The NAO's central VFM team periodically prepare summary reports for senior management, which highlight: the lessons learned from quality assurance reviews; the need for action to promote improvements, such as training and guidance; and wider issues for further research and consideration. The key messages arising from quality assurance are communicated to VFM staff through seminars, workshops and guidance.

\section{Good Practices}

Some points to bear in mind with regard to quality assurance:

- Consider quality assurance as a continuous process and not just a one-off procedure or event after completion of the study;

- Determine at a very early stage in the examination the actions to be taken to promote quality;

- Seek a second opinion at key stages to validate, for example, study selection, questions to be examined, design and methodology;

- Identify critical points in the examination where review is especially required so as to ensure that the study will meet its aims;

- Utilise "hot edits" to help provide constructive comments for improving draft reports and presentation in general (but ensuring that suggestions are practical);

- Allow sufficient time for internal and specialist review of draft reports;

- Respond positively to the findings of external quality assurance reviews and to feedback from audited bodies, seeking clarification if their comments or concerns are not understood;

- Consider why some aspects of the study were more successful and others were less so;

- If a study exceeds its time frame or budget, identify the main drivers responsible for the overrun and consider what might be done in future (while not neglecting the benefits of hindsight);

- Ensure that the lessons learned from quality assurance reviews are widely communicated through workshops and seminars;

- Above all, adopt a positive approach: quality assurance reviews should not be negative post-mortems but an opportunity to be constructive and to learn from experience. 


\section{UNITED STATES ${ }^{14}$}

\section{Quality Assurance in the United States General Accounting Office (GAO) ${ }^{15}$}

\section{Introduction}

This brief paper summarizes GAO's approach to quality assurance, which does not focus exclusively on the audit process. Rather, the emphasis on achieving the highest possible quality of work pervades the institutional culture and is found throughout its management policies and practices.

\section{Independence, Integrity and Objectivity}

GAO adheres to the independence standards of its Government Auditing Standards. Staff members at all levels must also comply with applicable conflict-of-interest laws and regulations and are responsible for bringing potential conflicts of interest to the attention of superiors. They prepare annual financial disclosure reports, which reveal details of the staff member's income, assets and liabilities and those of a member of his/her immediate family. These reports are reviewed by more senior officials, whose own reports are available for public inspection. Staff members must also sign an annual Statement of Independence, and must obtain permission to engage in certain outside activities, including employment.

GAO has recently further tightened the standard for independence. Auditors, and the organizations in which they are employed, are barred from engaging in other significant work for the auditee. For example, if an organization has assisted an auditee in constructing its IT system, it may not subsequently be the auditor for that entity. This restriction primarily affects private auditing firms that may be engaged in auditing governmental entities.

\section{Human Capital Management}

GAO attempts to recruit individuals with outstanding intellectual capacity, technical and interpersonal skills, and leadership capabilities. The managing director in each audit area (equivalent to Assistant Auditor General) determines the staff composition needed to meet the objectives in that area. These requirements are referred to central management, which must reconcile them with the available budget resources and decide how many can be hired in each area. To fill the positions, GAO recruits at selected universities, but also hires from other sources.

In the financial management area, GAO typically recruits people with a strong accounting background. In the performance audit areas, the relevant disciplines are much more diverse, including public administration, economics, information technology and many others.

Individuals are selected after interviews with several staff members at management level. GAO then provides an orientation program for new employees. Newly hired staff and staff members transferring from one audit area to another attend courses on the relevant audit methodology and other pertinent subjects.

GAO provides formal classroom training and individual study programs, some of which are available online. Much of this training is developed and administered by the Center for Performance and Learning.

\footnotetext{
${ }^{14}$ Contribution prepared by Harry Havens, SIGMA expert (received on 30 October 2002)

${ }^{15}$ In 2004, GAO's name was changed to the "Government Accountability Office".
} 
In addition, however, financial audit groups have developed and present some specialised courses in that area.

All auditors must obtain at least 80 continuing professional education (CPE) credits in each two-year period, including at least 24 credits directly related to the government environment and government auditing. Compliance is closely monitored.

Staff members are evaluated at least annually by their superiors against published performance dimensions and standards. GAO promotes staff members based on performance and the demonstrated willingness and capability to assume greater responsibility. Vacancies are widely announced, for which individuals may apply. Candidates are assessed by annual selection panels, which make recommendations to the selecting official, typically a managing director.

In assigning staff, the objective is to ensure that each audit team collectively possesses adequate professional proficiency, while also assuring that staff members can further their professional development. Individuals are assigned to audit groups based first on the needs of the group, but also with consideration of the individuals' needs for particular types of experience. The director of the group assigns the individual to a specific audit, working for an assistant director or auditor-in-charge, who manages the work.

Each audit team is staffed with appropriate skills. Financial statement (attestation) audits are always led by a Certified Public Accountant (CPA), who is experienced in performing such audits.

\section{Audit Performance}

GAO prepares a five-year strategic plan for its work. This work is of three types: congressionally requested, legislatively mandated, and research and development work based on GAO's basic legislative responsibility.

GAO has a published Congressional Protocol for guiding its relationship with Congress, which includes procedures for negotiating the terms of a request and for confirming the acceptance of a request. The Comptroller General can decline congressional requests if he judges them to be inappropriately political in nature or outside the scope of GAO's responsibilities.

The decision to initiate an assignment is approved at an Engagement Acceptance Meeting involving GAO's top management, at which point the participants also agree on the risk level of the assignment, which determines the subsequent level of review of the work.

Primary responsibility for each audit lies with the "first partner", who is typically at the director level, immediately below a managing director. The first partner plans and supervises the audit, together with assistant directors and auditors-in-charge. After gathering advice from throughout GAO, as appropriate, the planning judgments involved in a financial audit are documented in the Design Matrix, the General Risk Analysis, and the Account Risk Analyses.

Relations with the auditee are established through an Engagement Letter and an Entrance Conference, in which the audit's objectives, scope, methodology and timing are set out. Toward the end of an audit, there is an Exit Conference with the auditee to discuss the facts gathered in the audit.

After completing field work, an Audit Summary Memorandum is prepared to describe the audit results and to demonstrate the adequacy of the audit procedures and the audit conclusions. A pre-defined Work Paper Set, Audit Completion Checklist and other tools help ensure that all necessary steps were performed. All 
relevant work papers are subject to at least a primary review, and key ones receive a secondary review before report issuance. All products are "referenced" by someone independent of the audit, who traces all facts and figures from the draft product to the work papers.

The first partner approves the report and other supporting documents. A second partner (another director not involved in the audit or the managing director) independently reviews significant matters. For financial statement audits, the second partner must be a CPA with significant experience in the area. Experts from elsewhere in GAO may be asked to review a draft report to help ensure the validity of the analysis and the correctness of findings and conclusions.

After completing the internal review process, all draft reports are sent to the auditee for review. Typically, 30 days are allowed for this phase. Any comments by the auditee are analysed and, if warranted, appropriate changes are made in the draft. Any such comments and the GAO analysis are published in the final report, which becomes a public document, unless distribution must be restricted for national security reasons.

There are frequent Engagement Review Meetings with the Comptroller General and other top staff to discuss the status and progress of significant audits.

\section{Consultation and Research}

Libraries are available throughout GAO to help meet staff members' needs for professional literature. In addition, an Audit Reference Library is available online.

Auditors are encouraged to seek advice from experts on matters outside the knowledge of audit team members. Many of these experts are found within the organisation, but GAO staff may also seek outside advice, when necessary.

\section{Monitoring the Quality of Work}

The Office of Quality and Risk Management carries out a Quality Control Assessment Program (QCAP) to carry out after-the-fact inspections of selected performance audits and financial related audits. Financial statement (attestation) audits are inspected by a team reporting to the managing director in that area. The inspections include review of working papers, tests of functional areas and staff interviews. The results are reported to management and staff, who prepare action plans to deal with the findings, if needed.

GAO has also begun to obtain external peer reviews of its audit quality. The first, covering the financial audit area, was completed recently and resulted in a clean opinion. A second, covering the performance audit area, is expected to be undertaken in 2005, covering work performed in 2004. 


\section{ANNEX C - PRACTICES IN PARTICIPANT SAIS}

\section{Introduction and Summary}

This chapter seeks to describe the status of quality control in the audit process in the SAIs of Albania, Bulgaria, Croatia, Cyprus, the Czech Republic, Estonia, Hungary, Latvia, Lithuania, Malta, Poland, Romania, Slovakia, Slovenia and Turkey. This information is drawn from replies to a questionnaire, supplied by participant SAIs between May and November 2002.

The extent, level and sophistication of quality control processes appeared to vary widely among these SAIs at the time of the questionnaire. Some had relatively extensive procedures that sought to ensure high quality throughout the planning, execution and reporting phases of the audit. Others were at a much more basic stage of developing their quality processes. From the SAI responses, one particular element of quality management needed to be introduced where it was not used (which appears to have been the case of most of the participants). This missing element was the post-assignment quality review by experienced auditors who are independent of the audit under review. These reviews should be performed, after the fact, on an appropriate portion of an SAI's audits each year. The purpose is not to criticise the selected audits, but rather to determine:

- whether existing quality control procedures are being applied consistently and effectively; and

- how SAI quality control systems can be improved and strengthened.

In considering the information provided in this annex, the reader should recognise that the data reflects the situation at a particular point in time and is likely to have changed to some degree in the meantime.

\section{General Issues}

Most participant SAIs have taken steps to establish at least the basic elements of systems to control the quality of audit proceedings. To gain the appropriate level of commitment to quality, it is vital that emphasis on this matter starts with the head of the SAI. This commitment at the top appears to be the case in most, if not all, of the participant SAIs.

The problem of developing quality can be considered at two levels:

- ensuring better functioning of existing elements of quality control;

- co-ordinating existing elements, adding others as needed, and ensuring a coherent approach to quality control in the audit process.

In some SAIs - such as in Lithuania, Poland, Romania and Slovakia - audit quality control mechanisms are currently being transformed and expanded.

Basic factors to ensure quality control are the establishment and practical application of auditing standards and methodological guidelines, which highlight the obligation to carry out audits in accordance with specific audit procedures and methodology. Until recently the relevant regulations adopted in some participant SAIs covered mainly audit procedures and only partly audit methodology. New and broader regulations have nevertheless come into effect in recent years. According to a SIGMA survey carried out in June 2002, of the 13 responding SAIs, nine have in place their own auditing standards while the remaining four are in the process of preparing these standards. 
Occasionally, as in Bulgaria and Lithuania, a new State Audit Act clearly stipulates that the SAI is to issue auditing standards or other regulations of this kind. Some new State Audit Acts - in Estonia and Lithuania - contain references to commonly adopted auditing standards. Alternatively, an SAI may, in its internal regulations, direct compliance with specific international standards; this is the case in Croatia, Hungary and Poland.

To provide quality control and assurance, the criteria for assessment of audit work need to be defined by an SAI. Such quality criteria then need to be applied by auditors and management. For example, the assessment criteria should include:

- appropriate use of national and international auditing standards;

- appropriate use of guidelines and manuals;

- execution of audits in accordance with the annual audit plan and with detailed audit programmes.

In the majority of participant SAIs, quality control-related issues ensue from auditing standards, regulations or manuals that define the different auditing processes. Some SAIs, such as in Slovenia, have separate and more quality-specific guidelines.

Quality control measures differ substantially between SAIs. Even within the same SAI, the measures applied may differ depending on the type of audit (regulatory or performance) or on its complexity. For example, an audit involving multiple audit teams in numerous locations, such as the Polish "co-ordinated audits" (which may cover up to 100 auditees and are carried out in accordance with a uniform programme by up to 20 audit units), requires more complex management and quality control measures than the more typical arrangement of one audit team working in one location.

\section{Audit Planning}

Audit planning has two distinct phases. The first is the process by which the SAI determines which audits to perform. The second phase is the process by which the SAI determines how to go about carrying out the audits it has decided to perform. It is necessary to ensure high quality decisions in both phases.

\section{Selecting Entities and Activities for Audit}

Quality control in this first planning phase seeks to ensure that audit resources are used in the most efficient way possible and are applied to the highest priority audit objectives.

In the majority of participant SAIs, audits are planned for the following year. The annual audit plan serves as the basis for preparing detailed programmes for particular audits. In addition, in some SAIs, priority audit directions for longer periods are specified, typically for three years (e.g. in Malta and Poland). These mid-term plans or strategies identify problem areas of particular importance from the standpoint of the state and the economy (e.g. economic restructuring or risk of corruption). General priority-setting makes it possible to include in the audit plan a variety of topics, while at the same time setting up a barrier to limit other suggestions.

In some cases there is a practice of "rolling planning" (e.g. in Hungary). This means that annual plans are prepared when updating the three-year mid-term plans. Another approach is the adoption of audit plans for a multi-year period. 
In the audit planning process, priority must be given to those tasks that are required by law (e.g. auditing the execution of the state budget). These mandatory audits may absorb up to 60 per cent - or even more of available audit resources. The process of deciding how best to deploy the remaining audit resources varies widely among participant SAIs. It may be left to the initiative of individual audit units, or the proposals may originate at more senior levels of the SAI. In any event, it is essential that this part of the audit plan be approved by the head of the SAI to ensure that it conforms to the SAI's overall priorities.

In many SAIs, such as the SAO of the Czech Republic, audit units regularly create and update permanent data files on potential auditees in the area under their jurisdiction, which can be very helpful in setting audit priorities and in developing the audit programme for individual assignments.

Work on designing particular audit topics is carried out mainly in SAI audit units. Most often, proposals (with justifications) are presented by high-ranking staff members. The director of the respective unit checks the correctness of the proposal (including compliance with priorities and formal feasibility of the audit task) and assesses the purposefulness of assuming a given audit task, taking into account the guidelines set by the SAI's top management. Audit topics submitted by parliamentary committees and other public bodies are also considered.

Some SAIs - for example, the SAO of the Czech Republic - use a "proposal box". After analysing the collected information, the audit unit elaborates specific proposals for audits. The unit director places them in the unit's proposal box and regularly presents them to the senior director. The senior director then decides which proposals will be recommended.

As a rule, for draft proposals supported by audit units (or other internal bodies, such as senior directors or SAI members), clear assumptions are developed before they are passed to the SAI's top management. The draft proposals specify, among other things, the audit objectives, period to be audited, justification for the audit, possible results, basic audit topic, risk areas, audit timetable, and estimate of required resources.

Descriptions are compared and ranked using audit selection criteria that have been set out in the SAI audit strategy. Typically, a planning department or similar support unit carries out this task. Next, the draft annual audit plan is submitted to the relevant SAI decision body (senior director, SAI head or council).

Typically all unit directors, advisors to the SAI head, and SAI top management review the draft plan. Finally, the SAI head or council (or another relevant SAI body) approves the annual audit plan.

\section{Planning Particular Audits}

The second phase of audit planning consists of developing, agreeing and adopting the document that specifies the course of a given audit task, referred to as "the audit programme". The main elements of quality control are the obligation that the audit programme provide for collection of the information specified in internal SAI rules and participation of many SAI units and decision bodies, who review, discuss and accept the draft audit programme.

In the Polish co-ordinated audits, the draft programme is usually developed by the person who will be the audit co-ordinator, who takes account of a wide range of issues, including parliamentary concerns. A preparatory audit is often carried out in a body that is typical of the entities to be covered by the full audit.

In some SAIs (Malta, for example), an important element in the preparation of some regularity and all performance audit programmes is the so-called "pre-audit". Pre-audit work is carried out to establish whether there is sufficient basis for carrying out a full audit and whether a full audit is feasible. 


\section{Audit Execution}

In this phase, the team leader and other auditors carry out the audit fieldwork. It is essential that, before beginning the actual fieldwork, all members of the team have a clear understanding of the audit tasks and how they are to be performed.

In all SAIs quality control of audit execution is carried out at various levels. This control begins with the basic rule that each team member is personally responsible for the quality of his/her work.

In addition, the team leader must direct, supervise and review the work of the team on a day-to-day basis, ensuring that the work is carried out in accordance with the SAI's general rules and with the audit programme. Also, depending on the duties specified in SAI internal rules, more senior managers may need to be in contact with the audit team, review the audit work step by step, and when necessary for important issues, report regularly to the SAI's top management. In a large majority of participant SAIs, procedures seem to be in place for effective supervision and review during the execution phase of the audit. In the Maltese NAO, for example, the principal auditor prepares a report, at the end of each stage of an audit, on all findings made in the course of the work. The audit manager reviews these reports for adequacy.

An important element of quality control is the proper documentation of audit work. In the Audit Office of Cyprus, for example, the review of the audit file is carried out by the section leader, principal auditor and, in key areas, by the audit director. It is ensured that working papers are properly documented, crossreferenced and signed, and that permanent files are regularly updated.

Another important element of quality control in audit execution is the obligation to collect information specified in SAI internal rules and to ensure the participation of many persons to review, discuss and - in some SAIs - accept the draft audit protocol or proposed audit findings before they are incorporated in a draft report or discussed with the auditee.

Several SAIs have a system for monitoring the time and budget spent on conducting particular audit undertakings. In the State Audit Office of Estonia, for example, all audits have a deadline and a limit in terms of working hours. The time reporting system compares actual audit work with the approved time limits and deadlines. The head of each audit department makes a monthly progress report to the head of the SAI on all audit projects and on the main questions raised in audit projects.

\section{Audit Reporting}

Audit reporting is carried out according to the SAI Act, auditing standards (the SAI's own standards or accepted international auditing standards), other internal regulations and the audit manual (if applicable).

The first objective of quality control at this stage of the audit should be to ensure that all statements, assertions, findings and conclusions are fully supported by evidence gathered during the audit process. The second objective should be to ensure that the resulting report is complete, accurate, objective, convincing, and as clear and concise as the subject permits.

\section{Preparing Draft Reports}

Preparing the initial draft of an audit report is typically the responsibility of the leader of the audit team, often with the assistance of other members of the team. Quality is enhanced at this stage if these individuals have a clear understanding of how the report should be prepared and what it should contain. In the State Audit Office of Croatia, the Audit Manual provides detailed reporting guidelines. According to the Reporting Standards of the State Audit Office of Latvia, at the end of each audit the auditor must 
prepare a written opinion, setting out the findings. The content of this opinion should be easy to understand and free from vagueness or ambiguity, including only information that is supported by competent and relevant audit evidence; the opinion should be independent, objective, fair and constructive.

\section{Internal Review of Draft Reports}

In most SAIs, one or more superiors in the organisation review the initial draft of an audit report.

Quality control procedures include review of the working papers and related draft report by the head of the section carrying out the audit/investigation, the relevant principal auditor and, in key areas, by one or more higher-level officials. The review ensures, among other things, that working papers provide sufficient information and are properly cross-referenced and that all audit findings have been evaluated as to their materiality and legality and are based on factual, reliable audit evidence. Working papers should indicate the persons who prepared and reviewed them. Great care must also be taken to ensure that the language used is easily understood and that findings/recommendations stated in the reports are supported by sufficient, relevant and reliable information.

While procedures vary widely among participant SAIs, all appear to have made adequate provisions for internal review of draft reports, which typically involve multiple levels of review.

\section{External Review of Draft Reports}

Typically, draft reports are discussed with the auditee, and in many SAIs the auditee's views (perhaps in a summarised form) are included in the final report. This involvement of the auditee can constitute a vital element of quality control, as the auditee is a well informed party with an incentive to challenge adverse findings if they appear to be incorrect or insufficiently supported by audit evidence. At the same time, it must be recognised that the auditee is an interested party, who may wish to minimise the credibility or significance of adverse audit findings. Thus, while the auditee's views must be given fair consideration, it is incumbent upon the SAI to examine those views carefully and to determine the weight they should be given, including this analysis, if appropriate, in the audit report.

Most, if not all, of participant SAIs provide for a contradictory procedure.

\section{Other Matters}

In many SAIs - for example, in the Audit Office of Cyprus - any events relevant to the audit which occur between the date of preparation of the report and the date on which it is issued are considered and, if material, included in the final report. Failure to do this can undermine the credibility of the report.

Another normal and useful practice is the publication of audit reports, in either paper or electronic version. This can enhance audit quality in two ways. First, such reports are likely to be read by experts in the subject addressed in the report, who may offer useful suggestions for future audits in that area. Second, auditors' awareness of the wide dissemination of reports may cause them to be even more careful in their audit work. On the other hand, wide distribution of critical audit reports, especially in politically sensitive areas, can elicit an unusually strong defensive posture by the auditee(s).

Finally, self-examination of a completed audit, by the audit team, can help the members of that team learn what they might have done differently or more efficiently. This self-examination can be a useful learning experience for team members and can lead to improved quality in future audits. The State Audit Office of Estonia, among others, uses this technique. 


\section{Internal Post-Audit Quality Review}

An effective quality management system must include procedures to determine whether or not the quality control measures that are intended to be used are, in fact, properly and consistently implemented, and to identify ways of strengthening existing quality controls. Experience has shown that this can be best accomplished by carrying out an independent, detailed, after-the-fact review of a sample of completed audits.

Several, but not all, participant SAIs either have such internal review processes in place or are setting them up.

\section{Peer Review}

Many participant SAIs have requested a peer review co-ordinated by SIGMA to help support their efforts to strengthen and improve the quality of their institutions. The fact that the reviewers are senior officials with many years of auditing experience - from different SAIs, employing different methodologies, has greatly enhanced the value of these reviews. It is clear that this has been a very useful process for SAIs in reviewing their legislative, organisational, methodological, and other key functions.

\section{Conclusion}

It is evident that participant SAIs have taken important steps to establish and strengthen their processes for ensuring the quality of their audit work. It is equally clear, however, that for many of them, further action in this area should be a high priority. 


\section{ANNEX D - GUIDELINES ON AUDIT QUALITY}

The following guidelines are based on those approved by the presidents of the participating SAIs at their meeting in Riga in April 2004, with minor modifications to reflect subsequent discussions, but without the explanatory material in that document. The guidelines themselves, with accompanying explanatory and supplementary material, can be downloaded in electronic format from the following websites:

- $\quad$ www.SIGMAweb.org

- $\quad$ www.asz.hu

- $\quad$ www.nao.gov.mt

- $\quad$ www.nik.gov.pl

\section{General}

A Supreme Audit Institution (SAI) should seek to carry out its audit work at a consistently high level of quality in the following dimensions:

- $\quad$ significance and value of matters addressed in its audits;

- objectiveness and fairness in the basis of assessments made and opinions given;

- $\quad$ scope and completeness in the planning and performance of audits carried out;

- reliability and validity of the opinions, or findings and conclusions; appropriateness of the recommendations; and relevance of other matters presented in its audit reports and other products;

- timeliness of the issue of audit reports and other products in relation to statutory deadlines and the needs of anticipated users;

- clarity in the presentation of audit reports and other products;

- efficiency in the performance of audits and audit-related work; and

- effectiveness in terms of results and impacts achieved.

In pursuit of this goal, an SAI should establish policies, systems and procedures that will encourage actions leading to high quality and discourage or prevent actions that might impair quality. These quality controls should be developed and implemented with respect to all phases of the audit process, including:

- $\quad$ selection of matters for audit;

- decision on timing of the audit;

- $\quad$ planning of the audit;

- $\quad$ execution of the audit; 
- $\quad$ reporting of audit results; and

- follow-up and evaluation of audit findings, conclusions and recommendations.

\section{Selection and Timing of Audits}

An SAI should ensure that decisions on the areas to audit and the timing of audits give proper consideration to the following:

- relative priority among potential audit subjects, including consideration of audits required by law where applicable, and the limits of the SAI's mandate;

- financial and human resources required for the performance of particular audits, including consideration of the availability of audit staff with the required skills;

- time at which the results of particular audits are likely to prove most useful, including consideration of timing requirements imposed by law;

- potential need to revise audit priorities in response to changing circumstances;

- selection and timing of audits depending on the work of internal auditors or other auditors performing audits on the same bodies;

- $\quad$ assessment of risks, and significance, sensitivity and materiality of audit topics.

\section{Audit Planning}

In each audit, the first step should be the development of a fully documented audit task plan. The plan should be prepared by the principal auditor, or by another sufficiently expert and qualified auditor, preferably in consultation with other members of the team, if any, or with the collegiate structure. The plan should be developed with careful regard to, among other things, the following:

- number and skills of staff available for the audit;

- time, financial and other resources, including, where relevant, external expertise required for the performance of the audit; and

- risks that may be encountered in the audit and audit tests that will specifically address those risks.

The audit task plan should describe in sufficient detail:

- $\quad$ purpose and objectives of the audit;

- $\quad$ selection and calculation process for materiality;

- methodology to be employed;

- $\quad$ audit tasks to be performed; 
- time and other resources allocated to each of those tasks, along with identification of the person(s) assigned to the task and their responsibilities;

- $\quad$ scheduled completion date for each task, for each separate phase of the audit, and for the audit as a whole.

The audit task plan should be reviewed, modified if necessary, and approved by an official who has supervisory authority over the audit team, if the SAI structure has such a supervisory layer. Otherwise, the plan should be reviewed by another auditor of adequate seniority and authority within the SAI who has successfully performed audits of similar type and complexity, and who is independent of the audit team. All such reviews, and any approvals, should be documented.

\section{Audit Execution}

Before starting the audit, the principal auditor should ensure that:

- all those involved in the audit understand the plan as a whole and the tasks assigned to that person;

- $\quad$ each person involved in the audit has the skills needed to carry out the assigned tasks; and

- no conflict of interest or other factor could impede any person involved in the audit from carrying out the assigned tasks in a competent and objective manner.

The audit should be performed in accordance with the approved plan. However, the planning process does not end with the start of the execution phase. Rather, as implementation of the audit proceeds, unanticipated circumstances will often require that the plan be modified. Such changes should be documented, along with the reasons for them. If any changes alter significantly the methodology of the audit or the time or other resources required to carry it out, those changes should be reviewed and approved by the official, if any, who approved the original plan. Such approvals should be documented.

The principal auditor should maintain adequate supervision of those involved in the audit to ensure that the audit tasks are carried out properly. If anyone finds it difficult to carry out an assigned task, this should be reported promptly to that person's supervisor, who may need to provide further assistance. If significant unanticipated problems are encountered, or if audit results are obtained on material issues that are markedly at variance with those that were anticipated, these should be reported to the principal auditor, who may need to adjust the audit scope and/or audit task plan.

As each task in the audit task plan is completed, that fact and a detailed record of the results should be documented promptly by the individual(s) who performed the task. That documentation should be reviewed, evidenced and approved by the immediate supervisor of the responsible auditor, as well as by at least one other supervisor at a later stage in the audit. Reviews need to be clearly evidenced and dated.

Audit working papers are an essential part of the audit process. They should be systematically collected, reviewed and maintained. The working papers should be organised in a way that facilitates subsequent preparation and review of the audit report.

\section{Audit Reporting}

Audit reports should be clear, timely, concise and objective. They should provide a fair summary of all relevant facts. All findings and conclusions must be supported by adequate, reliable and fair audit evidence in the audit working papers. Reported audit issues need to be properly analysed and concluded. 
Viewpoints on significant issues of auditees expressed in the course of the audit on matters raised by auditors should be mentioned and discussed in the report. Any conflicting material evidence should be acknowledged in the report, together with an explanation of why it was rejected or otherwise not reflected in the report conclusions. The standards of materiality and significance will depend on the nature of the audit and the type of report or other output.

The draft of the audit report should be prepared by the principal auditor, normally in consultation with other members of the team, if any.

The draft of the audit report should be carefully reviewed for adequacy by an experienced auditor and/or audit collegium independent of the audit team. The principal auditor should respond appropriately to any comments by this reviewer. The review, any comments by the reviewer, and actions taken in response to the review should be documented and retained in the audit working papers.

After the draft report is reviewed internally, including - if appropriate - the collegial review, it should be provided to the auditee(s) for review and comment within a specified time frame. Comments received from an auditee should be carefully considered by the principal auditor and reported to the reviewer and, if applicable, to the audit collegium. Factual disagreements should be resolved, possibly necessitating additional audit work. The audit report should be adjusted, if appropriate, in response to factual, soundly based auditee comments.

There should be a clear statutory provision and internal guidance as to the person having the authority to approve and issue the audit report.

\section{Audit Follow-up}

At some time after an audit report has been issued, an SAI should take appropriate steps to determine the actions, if any, that an auditee has taken to correct the problems disclosed in the audit report and the effects that such actions may have had.

\section{Quality Assurance - Assessing Quality Controls}

An SAI should establish procedures for assessing its system of quality controls to:

- determine if the required controls are in place;

- determine if existing controls are being properly implemented;

- confirm the quality of the audit practices and reports; and

- identify potential ways of strengthening or otherwise improving the controls.

Quality control assessment procedures should include post-audit reviews of a selected sample of completed audits and the associated working papers, performed by individuals and/or groups that are independent of the audits under review. 


\section{Institutional Management}

To create an environment that is conducive to consistent high quality and to continually improving effectiveness, an SAI should give high priority to:

- managing human resources, with emphasis on:

$>$ recruitment

$>$ training

$>$ staff development

$>$ ethical standards

- managing institutional risks; and

- $\quad$ building effective external relations. 


\section{ANNEX E - DIRECTION, SUPERVISION AND REVIEW}

This annex provides guidance - based on the experience of advanced SAIs - on the key elements in managing the audit process: direction, supervision and review. The first section describes these functions as they are typically performed in a decentralised audit court, in which most management responsibilities are vested in the component colleges or chambers of the court.

The second section describes these functions as they should be performed in an SAI with a hierarchical management structure, which is typical of most "office-type" SAIs and of centrally managed audit courts.

\section{Direction, Supervision and Review in Decentralised Courts of Audit}

In decentralised audit courts, whether they are vested with judicial functions or not, the requirements for and key components of - direction, supervision and review are the same as those of an audit office, as described in the next section. However, there are significant differences regarding the processes and systems set up to achieve audit quality, which are related to institutional arrangements and structure, including:

- members enjoying a high degree of statutory independence (judges or equivalent status) and operational freedom in performing their duties;

- in some cases, a few layers of direction and supervision;

- in some cases, intervention of the Prosecutor General's Office, which is independent from the court;

- in all cases, collegial decision-making arrangements.

In this context, review processes may include the following features:

- $\quad$ work performed by audit staff is reviewed by "senior staff" members (or high-level magistrates) as in hierarchical structures and/or, alternatively, by "peers" (for instance, contre-rapporteurs), who provide their own views;

- in some courts of audit, a Prosecutor General or his attorneys may provide an independent opinion to throw light on the work performed, especially on legal matters;

- in all cases, audit work is reviewed by at least one college, and decisions are made collectively.

In addition, as far as judicial decisions are concerned, the contradictory procedure is subject to detailed and compulsory arrangements, including the possibility of appeal against rulings. These arrangements provide for full consideration of auditees' views and therefore contribute to audit quality.

\section{Direction, Supervision and Review in Hierarchical SAIs}

Whenever work is delegated to others, direction, supervision and review must provide reasonable assurance that such work is performed competently. A formal process of review of this work will also be necessary. The extent of these quality control procedures will depend on the competencies of the actual staff carrying out the tasks.

Direction: The appropriate direction of staff to which work is delegated involves informing them of their responsibilities and of the objectives of the audit procedures that they will be applying. It also involves 
informing them of the nature of the entity's business and possible accounting or auditing problems that may affect the nature, timing and extent of these audit procedures. The means of communicating audit directions - in addition to briefings, meetings and informal oral communications - include audit manuals and checklists as well as the plan for the specific audit.

Supervision: This is closely related to both direction and review and may involve elements of both. Staff with supervisory responsibilities perform the following functions during the audit:

- Monitor the progress of the audit to determine whether:

$>$ auditors have the necessary skills and competence to carry out their assigned tasks;

$>$ auditors understand the audit directions; and

$>$ the work is being carried out in accordance with the audit task plan;

- Identify the significant accounting and auditing issues raised during the audit and address these issues by assessing their significance and modifying the audit task plan as appropriate; and

- Resolve any differences of judgement between personnel and establish the appropriate level of consultation.

Review: Work performed by audit staff needs to be reviewed by more senior staff of appropriate experience to determine whether:

- $\quad$ work has been performed in accordance with the audit task plan;

- $\quad$ work performed and results obtained have been adequately documented;

- any significant audit matters have been resolved and if not, this has been reflected in audit conclusions;

- objectives of the audit procedures have been achieved; and

- conclusions expressed are consistent with the results of the work performed and support the audit opinion.

Also to be reviewed on an appropriate basis will be:

- $\quad$ audit programme and audit task plans;

- assessments of inherent detection and control risks, including results of tests of control and consequent modifications, if any, to the audit programme and audit task plans;

- documentation obtained from substantive procedures and conclusions drawn;

- $\quad$ accounts themselves, any proposed audit adjustments, and draft report.

It is also important, in the context of the above, that audit work files carry evidence that review has taken place. 


\section{ANNEX F - QUALITY ASSESSMENT CHECKLISTS}

The checklists in this annex are intended to assist reviewers in focusing on matters that should be considered in reaching judgements regarding the adequacy of an SAI's quality controls.

\section{Audit Planning}

Those reviewing the adequacy of audit planning may wish to consider the following matters:

- Ensuring that planning is carried out in accordance with auditing policies, standards, manuals, guidelines and practices of the SAI;

- Obtaining relevant information regarding laws and regulations that might have a significant impact on the audit objectives;

- Performance of preliminary investigative audit (audit aimed at conducting an initial study of specific issues to help prepare the audit task plan);

- Determining objectives and scope of audit;

- Identification of sources (e.g. media, findings of auditee's internal audit, inspection and other control bodies) as background for audits;

Determining list of activities for audit;

Highlighting special problems foreseen when planning the audit;

- Ensuring that members of the audit team have a clear and consistent understanding of the audit task plan;

- Follow-up of issues in previous related audits;

- Understanding of the finance, accounting and other relevant functions of the organisation;

- Identification of key elements of the internal control system of the auditee;

- Using appropriate analytical procedures;

- Identification and analysis of relevant ratios and comparative figures;

- Identification of trends or deviations from predicted amounts;

口 Identification of sampling method and sampling population;

- Choice of relevant performance indicators;

- Assessment of inherent and control risks;

- Establishment of materiality criteria and thresholds;

- Establishment of degree of confidence decided for audit; 
- Choice of appropriate experts/consultants;

- Preparation of budget and schedule for audit;

- Assessment of reasonable resources necessary to undertake audit;

- Assessment of staff requirements and team allocated for audit;

- Investigation and settlement of queries raised during review stage;

- Drawing up, approval and review of audit task plan by supervisors, if applicable;

- Other procedures and practices used in the planning phase of an audit;

- Practices to continuously enhance quality control procedures in the planning phase of audit.

\section{Audit Execution}

Those reviewing the adequacy of audit execution may find it helpful to focus on the following matters:

- Execution of the audit in accordance with auditing policies, standards, manuals, guidelines and practices of the SAI;

- Auditors' sound understanding of techniques and procedures, such as inspection, observation, enquiry and interviewing, to collect audit evidence;

- Execution of all phases of the audit as planned and approved;

- Valid explanations available for non-implementation of any significant areas in the audit task plan;

- Appropriate approval obtained for any significant deviations from the approved audit;

- Staff resources used for audit largely in line with those planned in terms of time, level of staff and expenses entailed;

- Justification available for material deviations from budgeted staff resources;

- Appropriate audit techniques and procedures used to fulfil each audit objective and provide effective audit evidence;

- Computer-assisted audit techniques (CAATS) used as appropriate;

- Appropriate tests used for evaluating the reliability of internal controls;

- Appropriate analytical procedures used, and reliability, independence and quality of relevant supporting data assessed;

- Sampling methods used according to the SAI's manuals and/or sound statistical methods;

- All tests of transactions clearly related to audit objectives, nature and extent of audit work adequately explained, and overall conclusion resulting from audit work provided; 
GOV/SIGMA(2004)1

- Audit steps and procedures designed to obtain sufficient and appropriate evidence;

- Full investigation of all queries raised during the audit;

- Adequate working papers available in respect of:

- evaluation of internal control systems;

- audit of routine procedures;

- tests of controls;

- analytical review;

- substantive tests; and

- audit of computer-based applications;

- Working papers appropriately cross-referenced;

a Comprehensive audit completion checklists completed, approved and duly evidenced;

- Work of consultants and other experts properly monitored;

- Other procedures and practices used in the execution phase of an audit;

- Practices to continuously enhance procedures in the execution phase of audit. 


\section{Audit Reporting}

Those reviewing the adequacy of audit reporting may wish to consider the following matters:

- Reporting in accordance with auditing policies, standards, manuals, guidelines and practices of the SAI;

- Form and content of reports in accordance with established procedures (e.g. title, signature and date, objectives and scope, addressee, legal basis, and timeliness);

a Terminology used in the report easily understood by persons to whom the report is presented and technical terms fully explained;

- All audit findings evaluated in terms of materiality, errors and other irregularities;

- All errors, deficiencies and unusual matters properly identified, documented and satisfactorily resolved or brought to the attention of a senior SAI officer, if applicable;

- Final audit report covering all areas that represent the objectives of the audit or explanations provided for omissions;

- Observations and conclusions in report supported and well documented to ensure completeness, accuracy and validity of working papers;

- All evaluations and conclusions soundly based and supported by competent, relevant and reasonable audit evidence;

- Only sufficiently material audit findings included in the main audit report;

- Report that is timely, comprehensive, performed by suitably qualified staff, appropriately documented and adequately incorporating the audit opinion;

- Letters of weakness/ queries/ management letters submitted to auditee in due time;

- Receipt of relevant and timely replies to SAI reports and other correspondence ensured;

口 Replies carefully studied;

- All observations that were contested by auditee duly evaluated;

- Relevant material comments by auditee referred to in the audit report;

- Relevant significant events occurring following completion of audit taken into account in the final audit report;

- All significant fraud or other irregularities notified to appropriate authorities;

- Permanent audit files updated to take into account the results of the audit;

- Material items requiring subsequent follow-up by SAI duly identified, recorded and taken into account; 
GOV/SIGMA(2004)1

- Other procedures and practices used in the reporting phase of an audit;

- Practices to continuously enhance procedures in the reporting phase of audit.

\section{Self Assessment and Obtaining Views of Auditees}

Those who decide that it would be useful to perform a "self-assessment" or to seek the views of auditees about the work of an SAI may wish to consider some of the following possible lines of inquiry:

\section{Adding value}

Was the focus of the audit too wide, too narrow, about right?

$>$ What insights into services did the audit provide?

$>$ What changes have been prompted or reinforced by the audit?

\section{Approach and methods}

Do you consider that the examination used suitable techniques for

- obtaining data?

- analysing data?

Was the auditee given the opportunity to comment on:

- aims of the audit?

- proposed methodology?

- appointment of consultants?

$>$ If negative answers are received, explanations should be sought.

\section{Working relationships}

To what extent was the audit staff courteous and professional in dealings with the auditee and its staff?

Was the auditee:

- $\quad$ kept up to date with progress?

- $\quad$ given an opportunity to comment as results emerged?

$>$ If negative answers are received, explanations should be sought.

\section{Contribution to modernising government}

To what extent did this report make a positive contribution to the following aspects of the government? 
- promoting good governance

- better financial management

- $\quad$ supporting innovation

- forward-looking

- citizen-focused

- $\quad$ supporting appropriate risk-taking

- improving the civil service

- outcome-focused

- better use of information technology

If negative answers are received, explanations should be sought.

\section{Fair and objective reporting}

Did the draft reports present the facts:

- accurately?

- fairly?

Were the views of other parties:

- incorporated?

- given a fair hearing?

How good and fair was the press coverage?

\section{General}

How would you rate the overall quality of the audit report(s)?

How effective was the report in making things better? Or in saving money? 


\section{ANNEX G - ISSUES INVOLVED IN POST-AUDIT REVIEWS}

\section{Opportunities and Risks of "Cold Reviews"}

\section{Opportunities}

An independent review, particularly if from outside the SAI:

- establishes whether the audit process is functioning efficiently and effectively and provides a fresh set of ideas;

- facilitates the quick implementation of lessons learned;

- provides hard facts attesting to the necessity of improving audit processes;

- encourages the continuous improvement process within the SAI;

- identifies areas of good practice that can be shared between colleagues.

Risks

On the other hand, an independent review may entail the dangers of:

- the focus of reviewers solely on weaknesses resulting in demotivation of audit staff;

- time-consumption and detraction of attention from other urgent tasks;

- lack of objectivity, in the case of internal reviews, resulting from a reluctance to criticise peers.

\section{What Post-Audit Reviewers may examine in Regularity Audits}

The reviewers may look into such issues as to whether:

- audit was properly planned and whether risks were identified and received the appropriate attention;

- $\quad$ sufficient work was performed to support the opinion in the audit report;

- conclusions are properly explained and supported by audit working papers;

- $\quad$ audit opinions are fully supported and documented in working papers;

- financial statements are presented in accordance with government accounting and other relevant regulations;

- $\quad$ working papers are in accordance with SAI policies and procedures. 


\section{What Post-Audit Reviewers may examine in Performance Audits}

The reviewers may look into such issues as:

- $\quad$ audit issues and scope;

- methodology;

- conclusions and recommendations;

- $\quad$ administrative and management context;

- $\quad$ structure, presentation and format;

- graphics and statistics.

\section{Required Elements for Post-Audit Reviewers}

Post-audit reviewers should:

- be qualified and experienced;

- be independent from the audit being reviewed (except for the team review);

- $\quad$ have the power to select the audits to be reviewed;

- $\quad$ have sound professional judgement;

- review audit reports, working papers and documents and carry out interviews with staff involved in the audits;

- have knowledge of quality control systems in place;

- prepare written, timely reports to communicate results of external quality control review and resulting recommendations. The latter should be constructive and balanced, taking into account the difficulties and constraints faced by the unit carrying out the audit. 